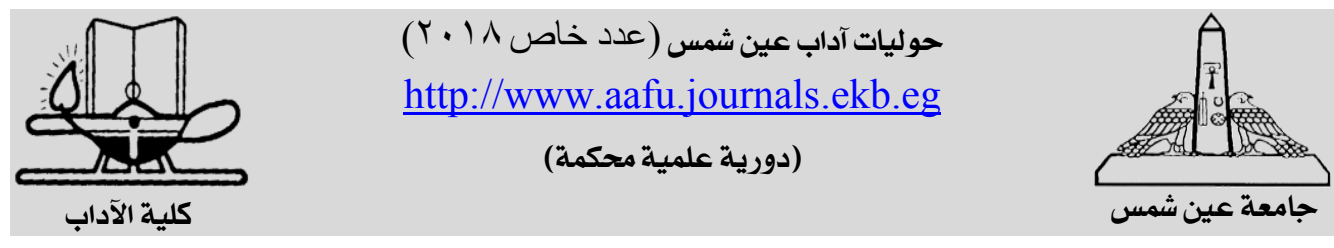

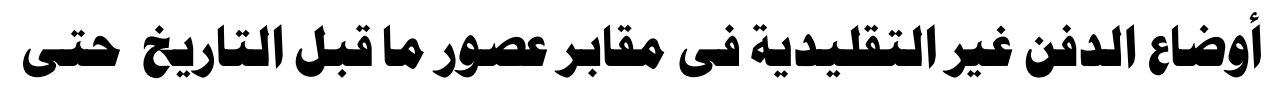

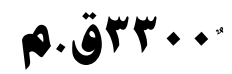

*نهال حمدى محمد سعيد حسن الانصارى

جامعة عين شمس - كلية الاداب - قسم الآثار - شعبة الآثار المصرية

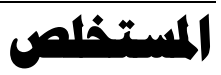

يتكلم هذا البحث عن الاوضاع الجنازية غير التقلبية فى مقابر عصور ما فبل

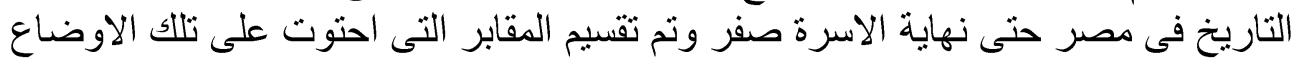
الجنازية غير التقليدية الى ثناثلاث مجموعات :

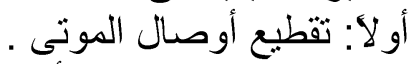

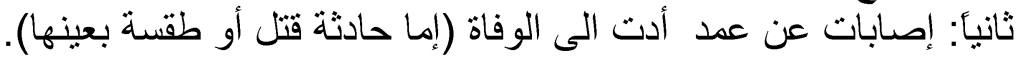

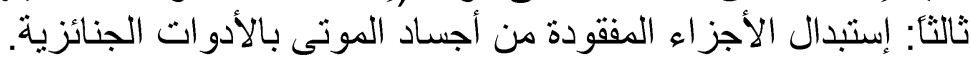

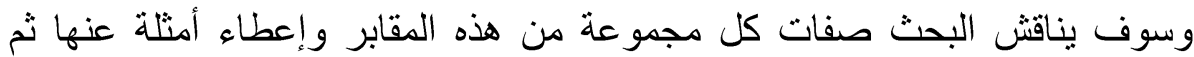
التعرف على الغرض الدين من الطقوس التى استخدمت فى المجموعات الثناث للمقابر . 
إن التغير ات التى تحدث فى المجتمع أثناء الحياة حتى الموت تؤثر بشكل طبيعى فى لهى

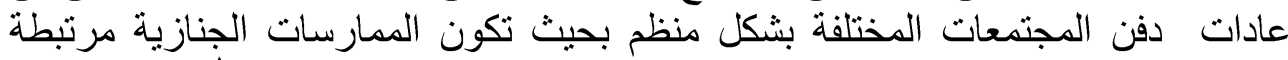

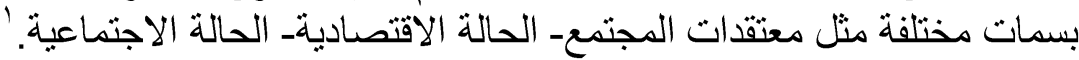

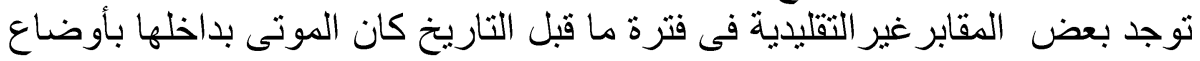

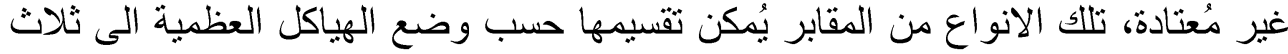

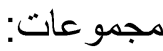
أولا: تقطيع أوصال المان الموتى (بتر). ثانياً: إصابات عن عمد أدت الى الى الوفاة (إما حادثة قتل أو طقسة بعينها).

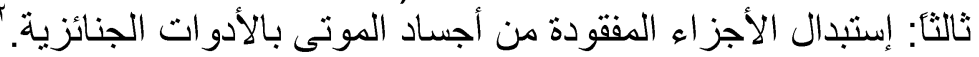

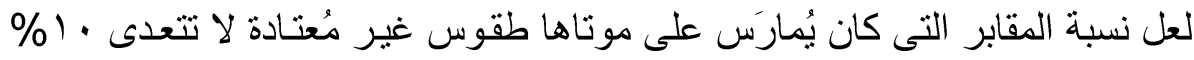

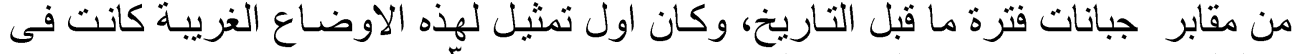

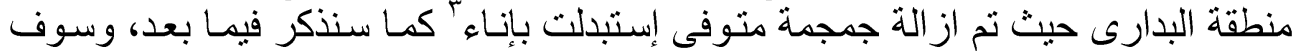

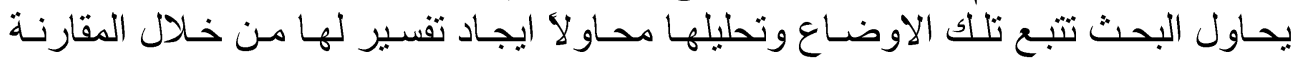
وربطها بالفكر الدينى عند المصرى نالإعى القديم.

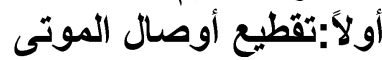

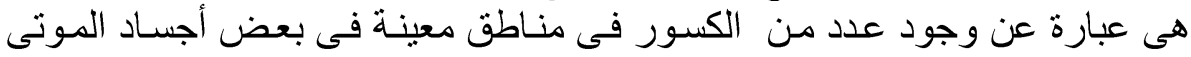

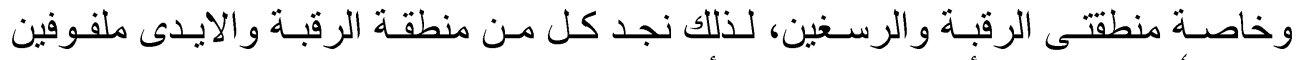

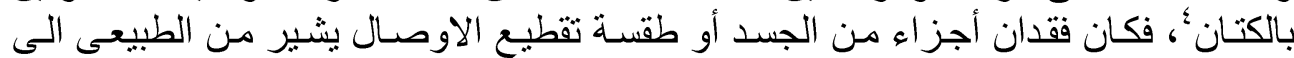

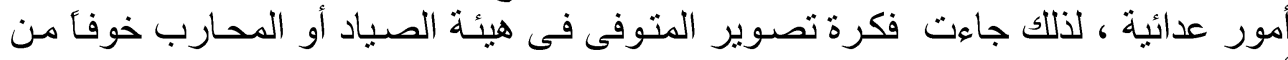

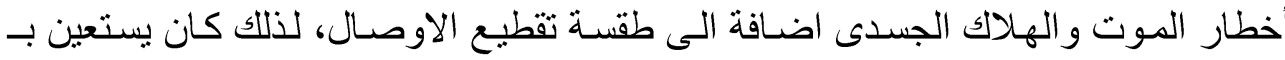

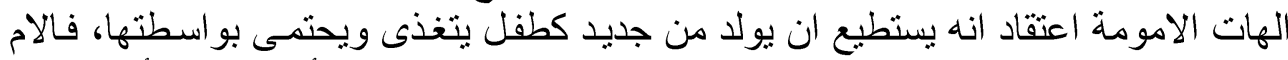

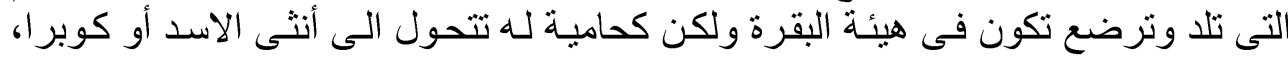

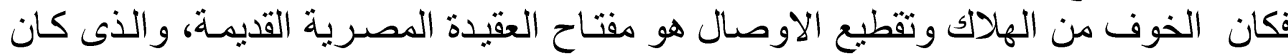

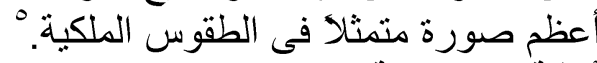

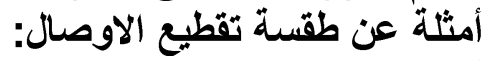

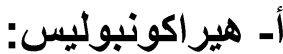

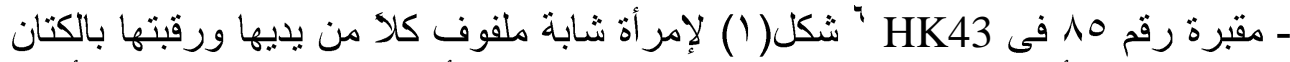

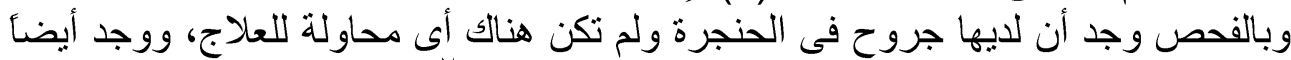

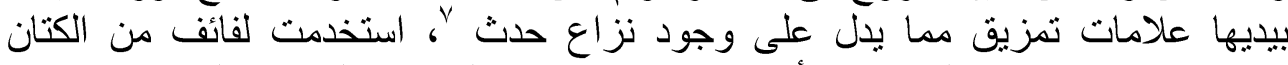
استخدمت فى لف مناطق فى الر أس مثل قاعدة الجمجمة، و الرقبة و الجبهة و الفك وبشكل

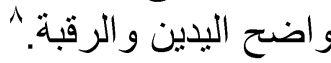

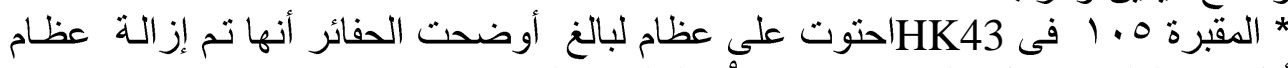

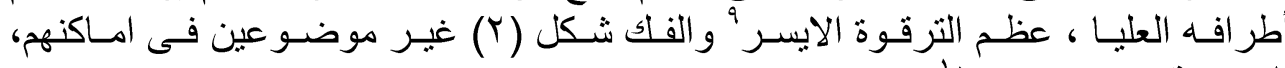

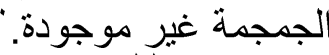

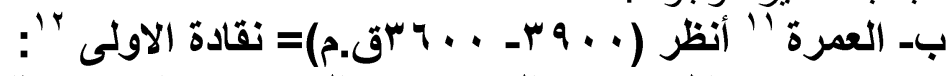

* مقبرة A96 شكل (T) من العمرة ترجع الى عصر نقادة IIC، ذكر العلماء أن متوفى هذه الأه

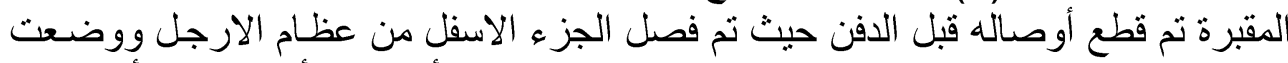

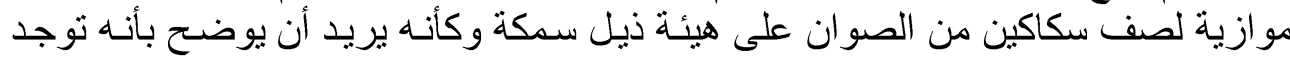

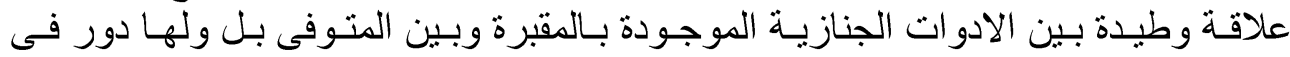


معالجـة الهيكل آعظمى نفسـه، وكانـت الادوات مرتبـة ترتيب دقيـق متتاسـب مـع الهيكل

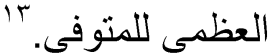

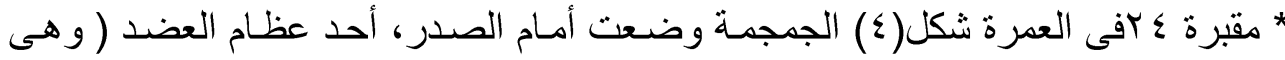

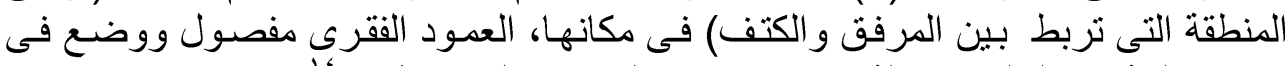

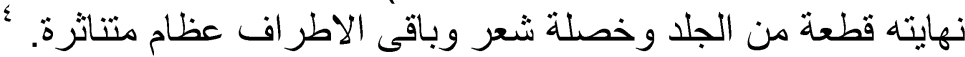

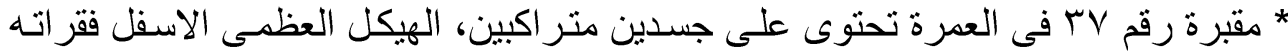

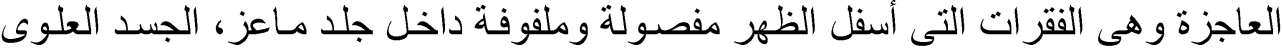

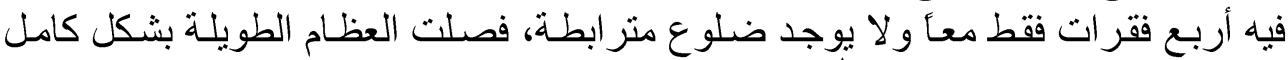

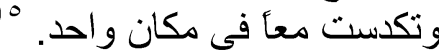

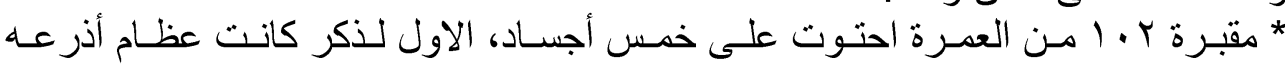

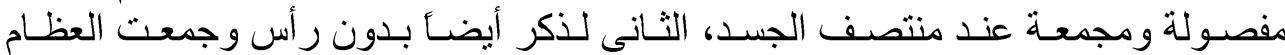

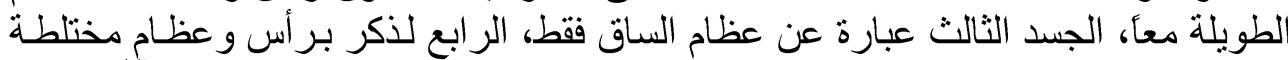

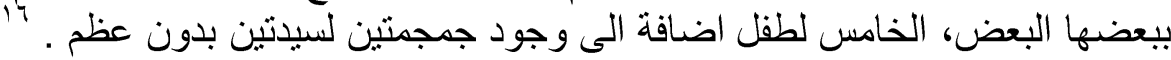

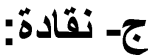

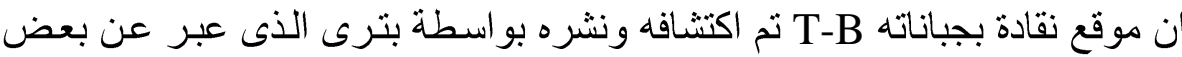

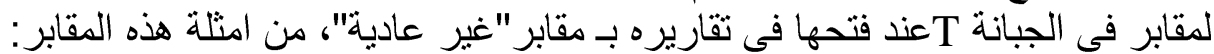

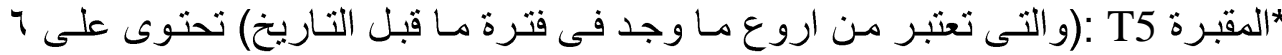

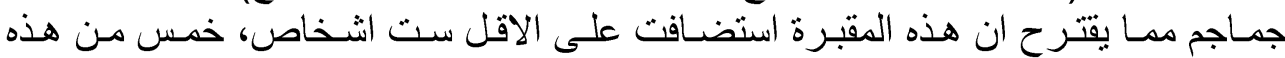

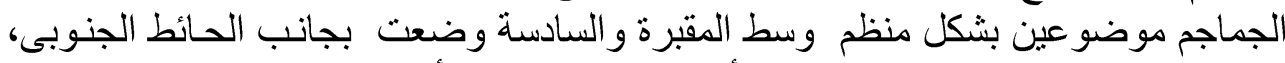

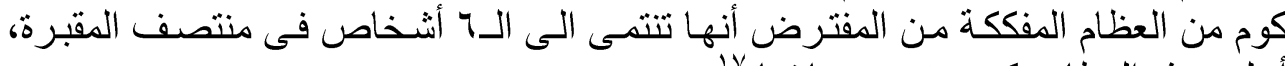
أغلب هذه العظام مكسورة العظد المغند نهايتها. * المقبرتين T19,T42: من المقابر المثيرة للاهتمام، كل مقبرة تحتوى على شخص وته واحد،

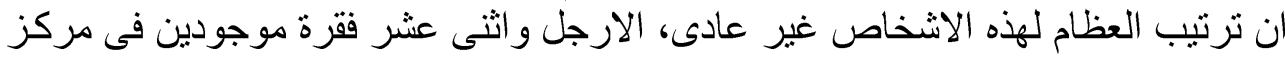

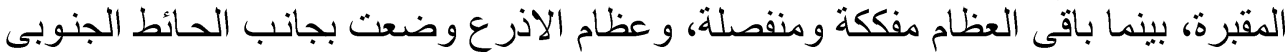

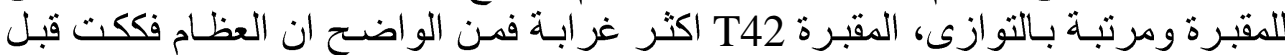

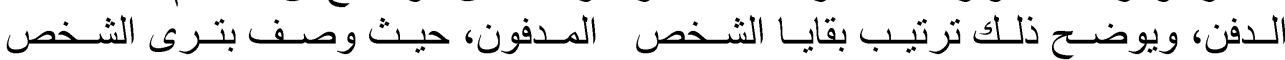

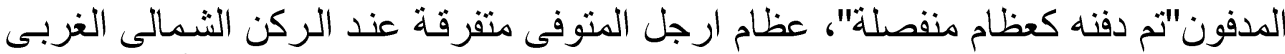

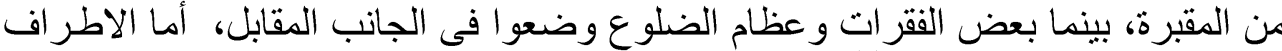

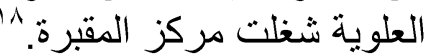

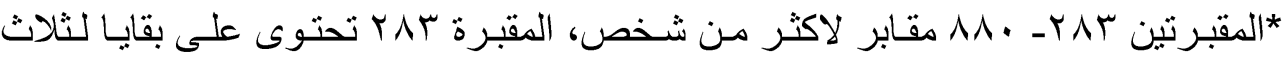

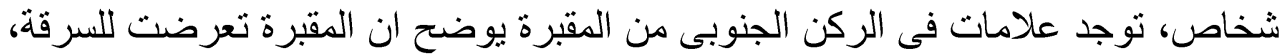

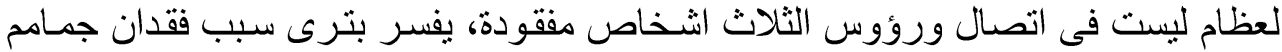

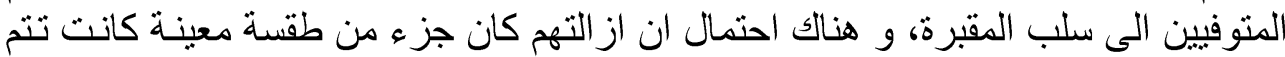

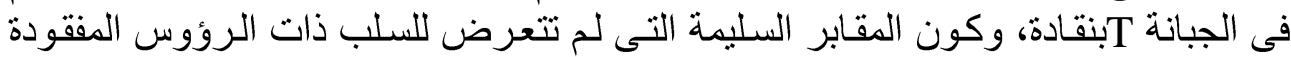

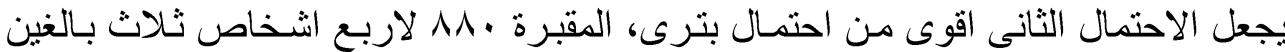

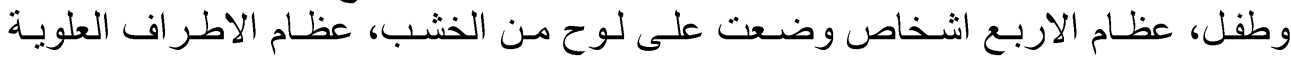

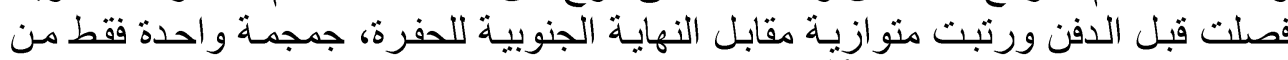




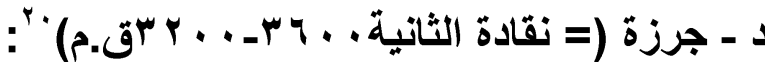

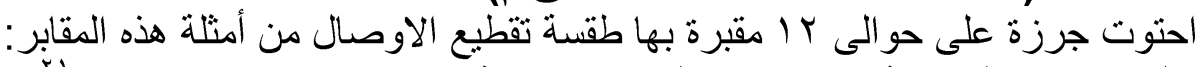

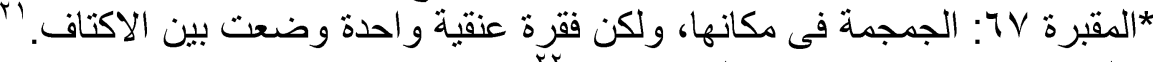

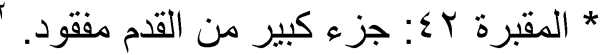

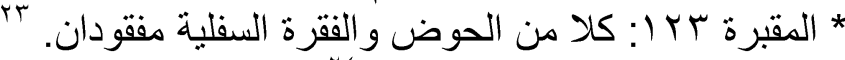

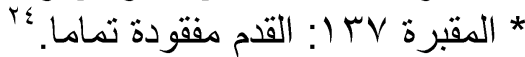

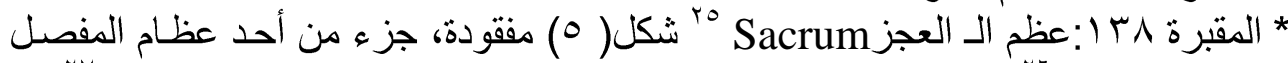

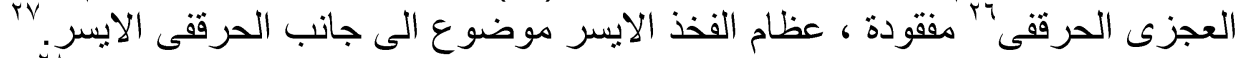

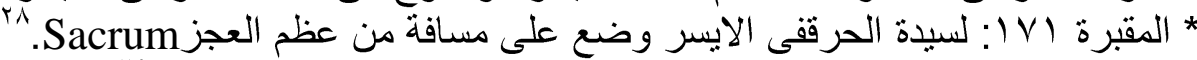

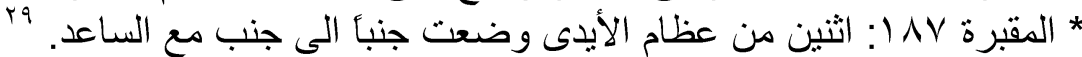

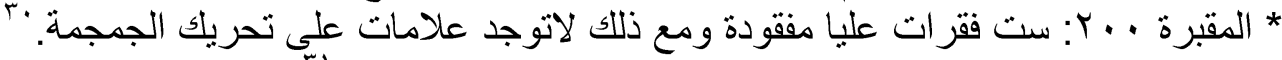

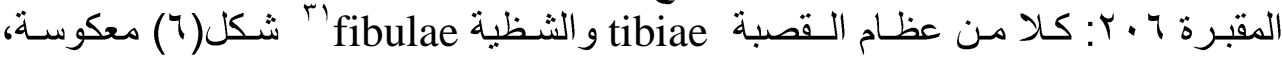

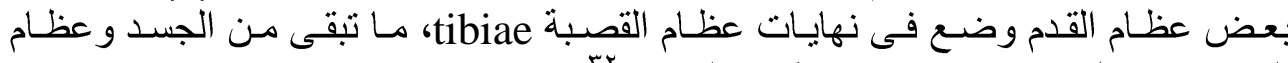

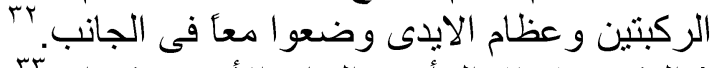

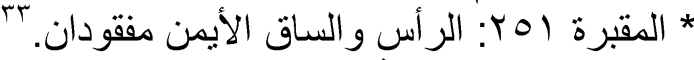

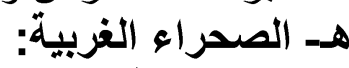

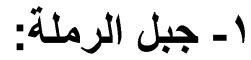

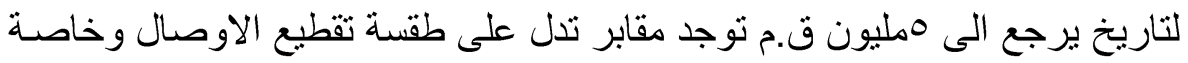

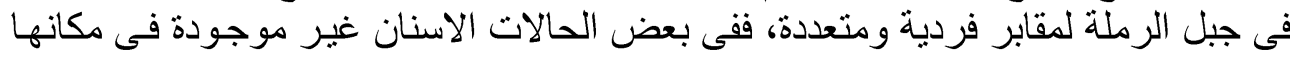

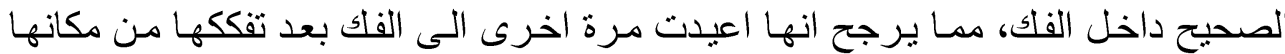

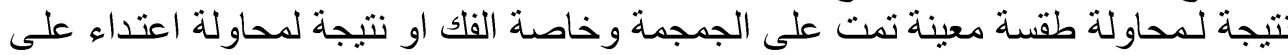

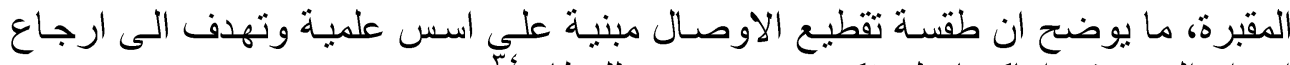

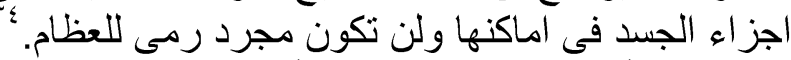

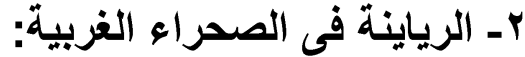

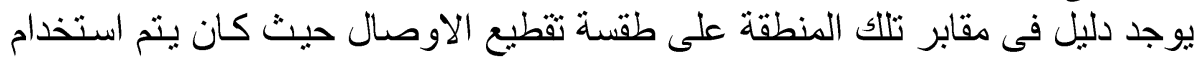

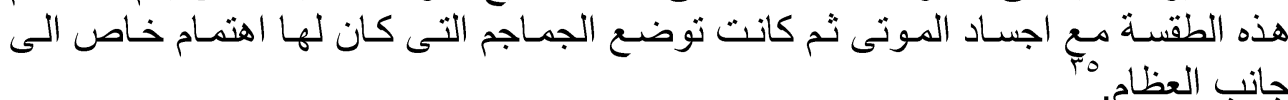
الغرض العملى والدينى من طقسة تقطيع الاوصال:

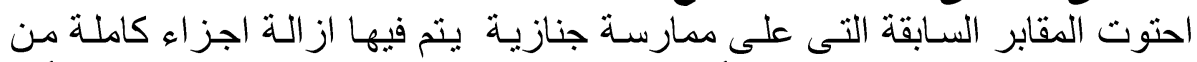

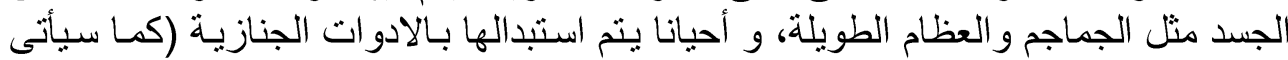

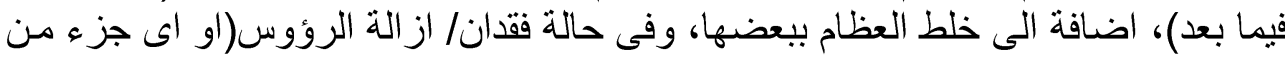

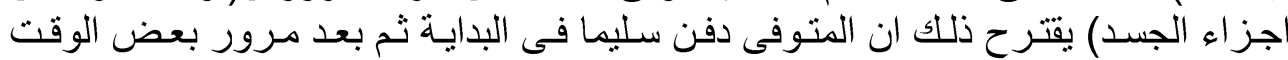

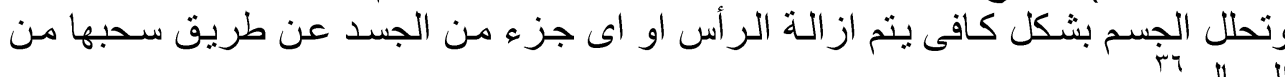

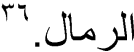

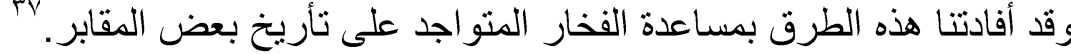

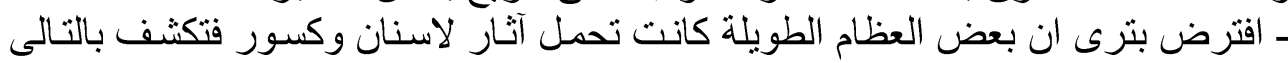

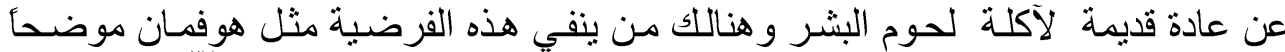

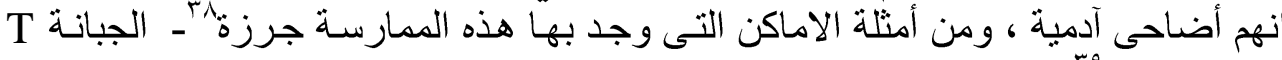

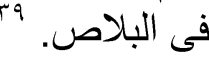




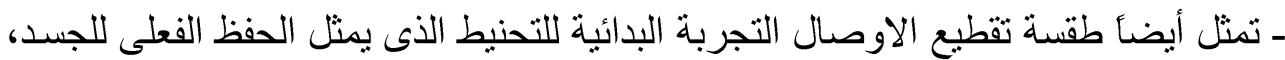

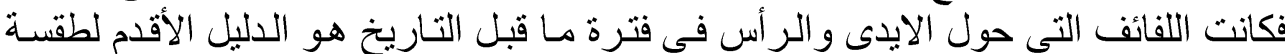

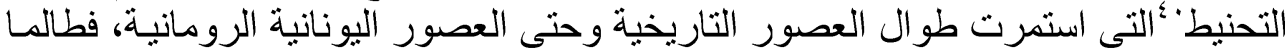

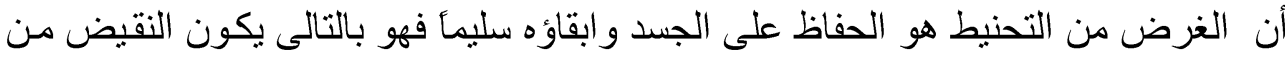

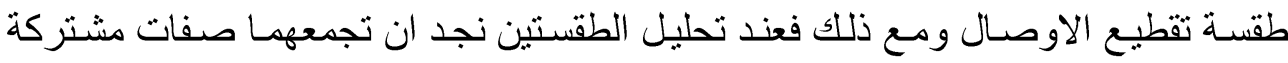

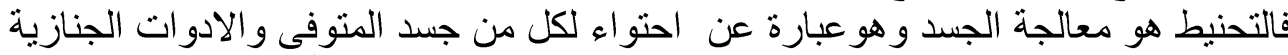

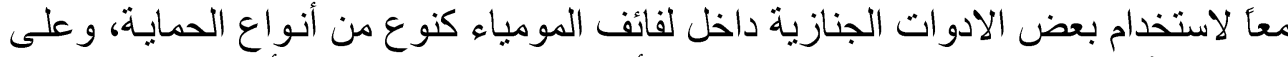

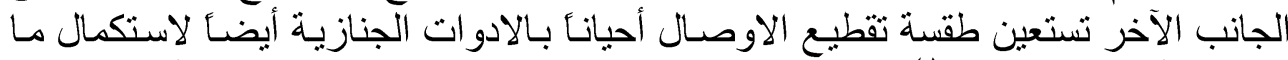

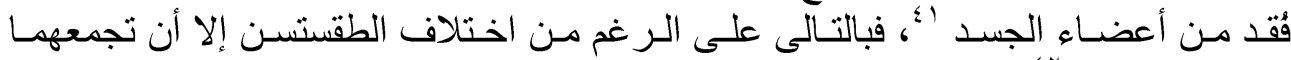

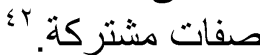

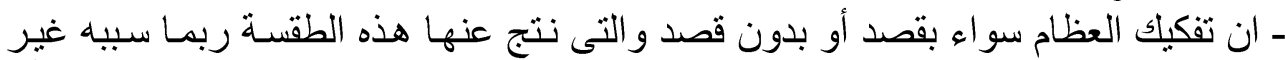

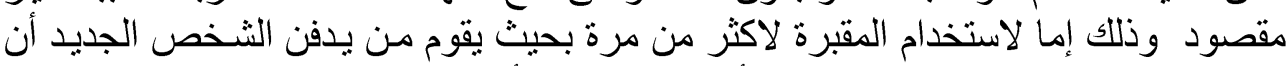

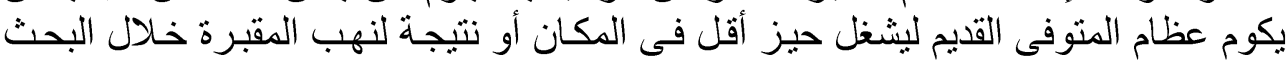

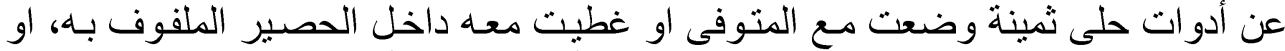

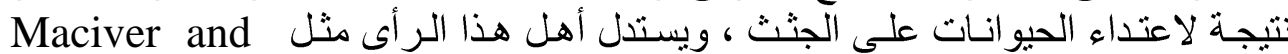
Mace

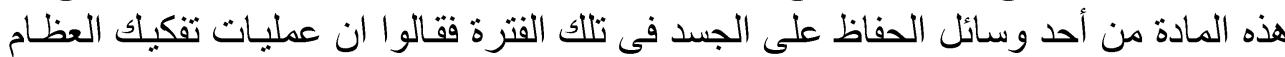

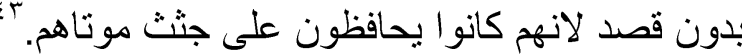

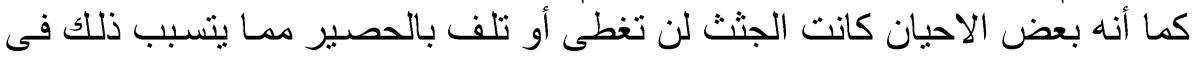

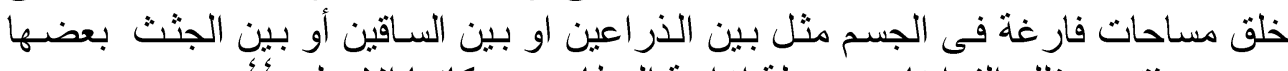

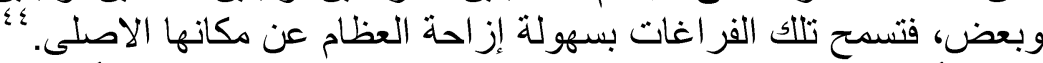

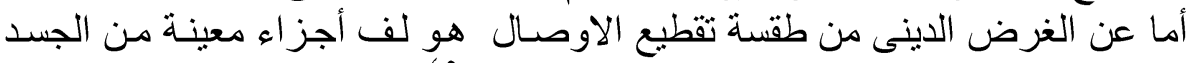

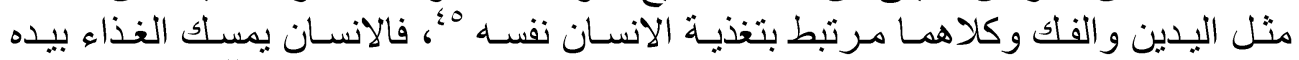

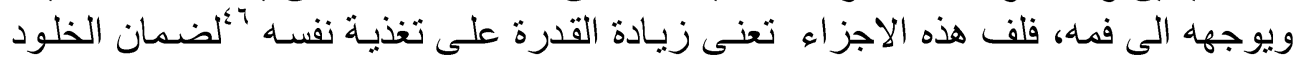

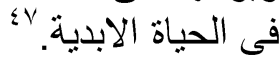

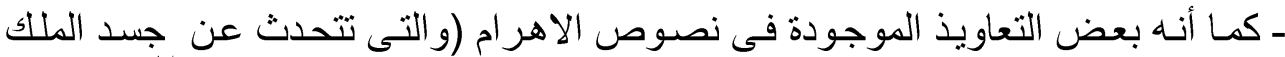

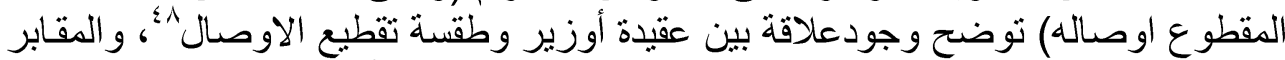

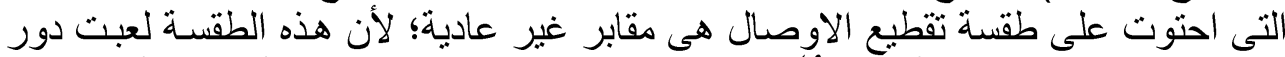

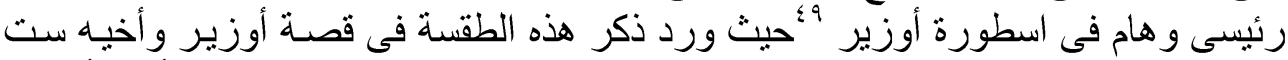

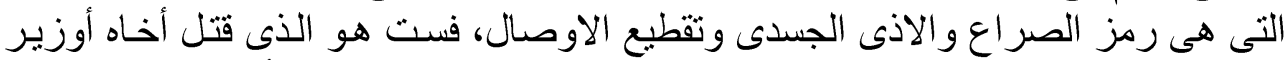

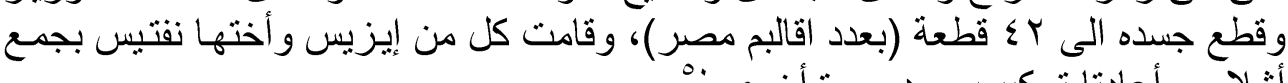

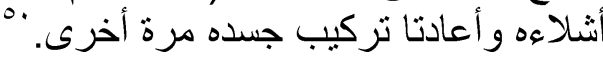

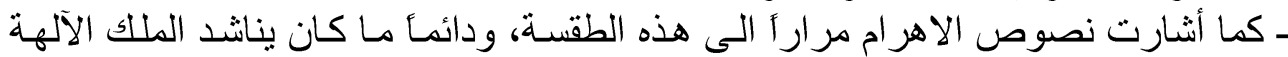

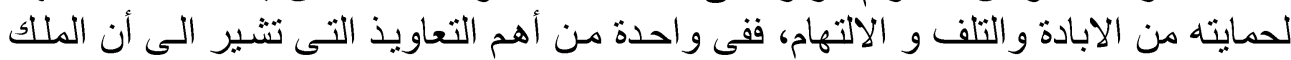

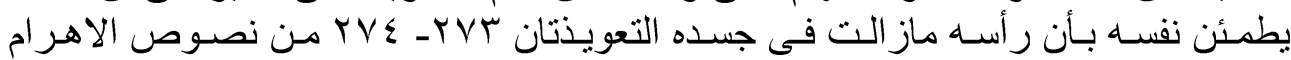

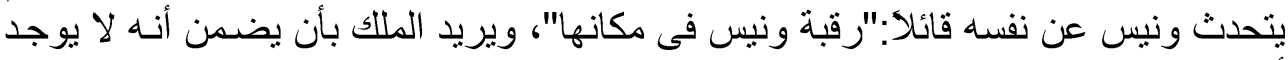

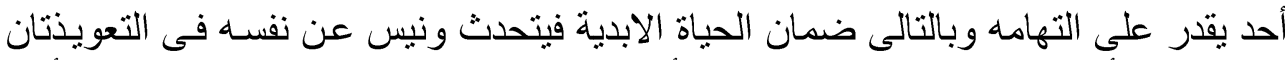

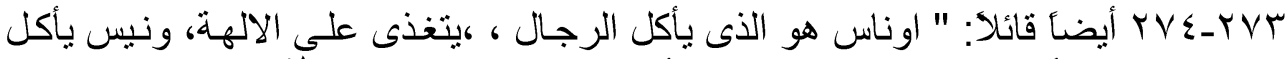

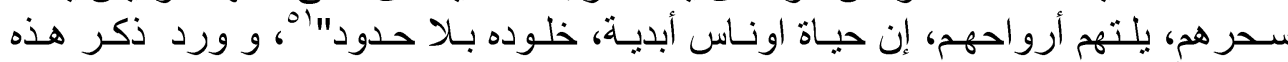

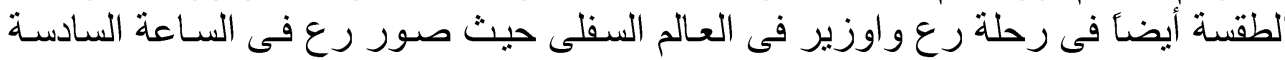


حسن الرحلـة فـى صـورة جعر ان مقطوع أوصـاله ويحساول فـى هذه السـاعة يعيد تركيب

ـ فكان المصرى حريص كل الحرص سواء فى فترة ما قبل التاريخ أو العصور التاريخية

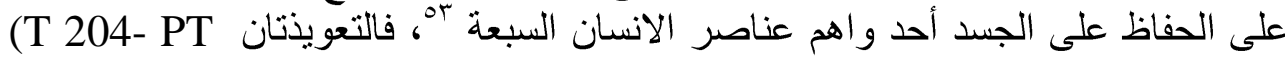

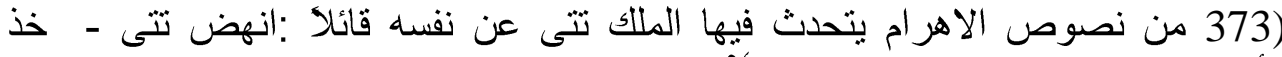

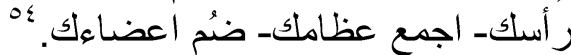

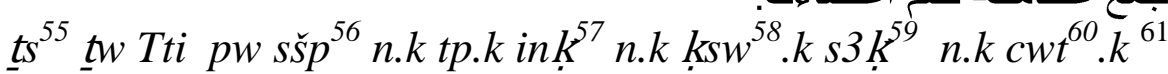

انهض تتى، خُذ ر أسك، اجمع عظامك،و اضمم اليك أعضاءك الك.

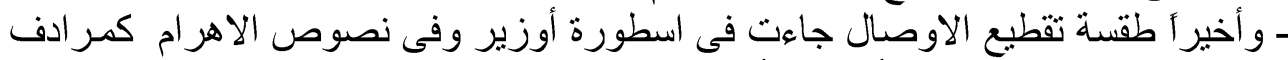

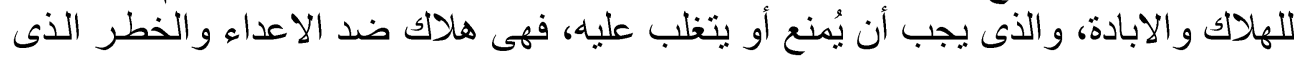

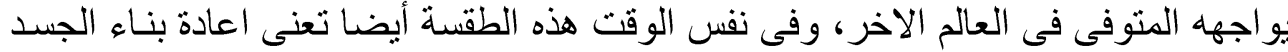

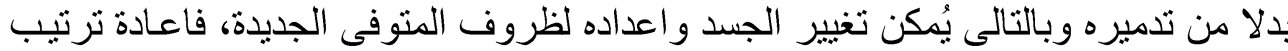

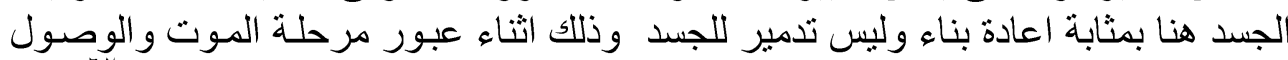

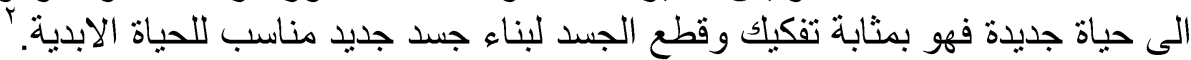

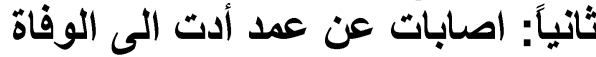

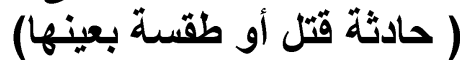

\section{تعريف الطقسة:}

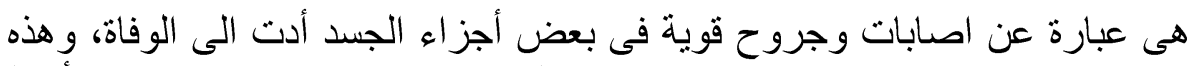

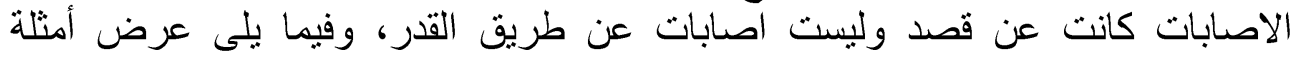

:HK43 - 1 :HK - أ

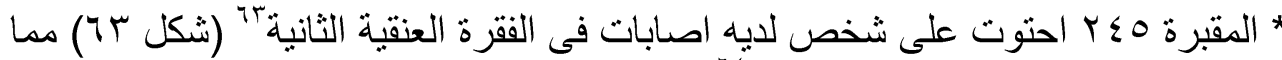

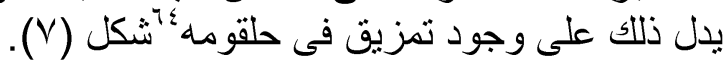

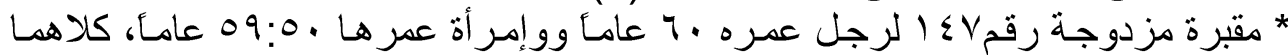

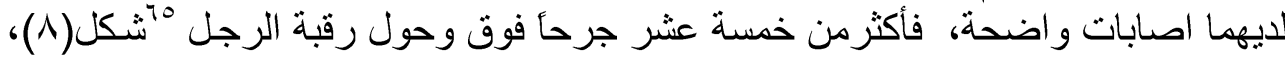

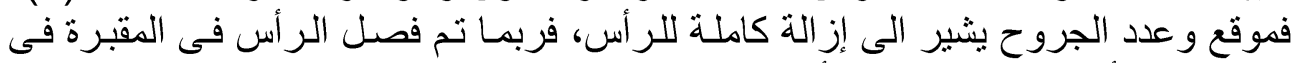

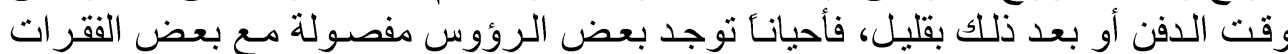

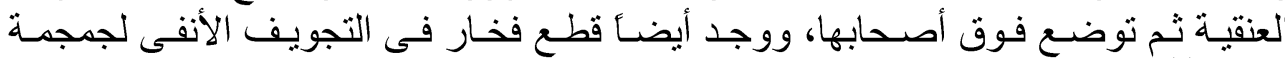

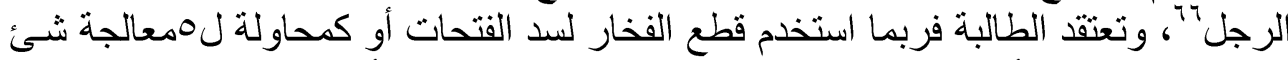

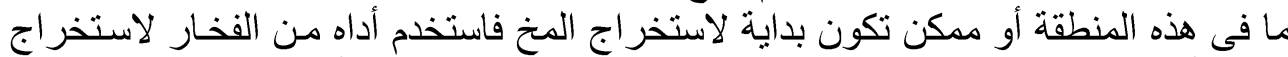

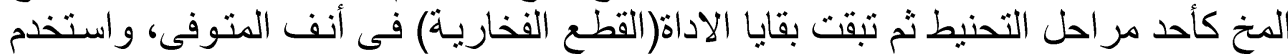

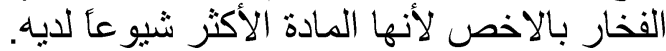

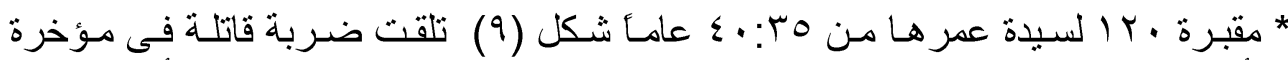

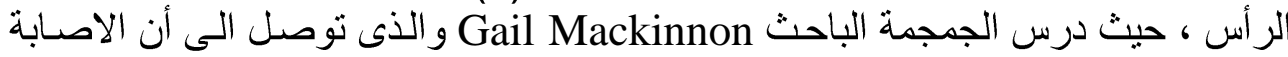

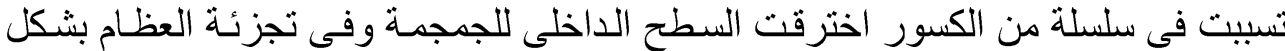

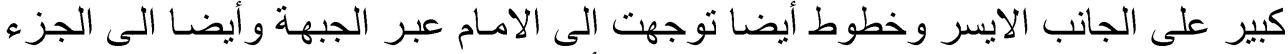

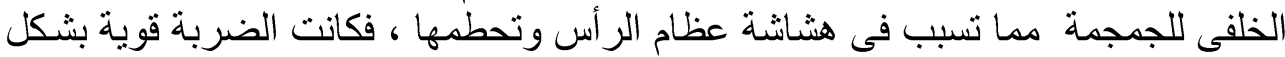

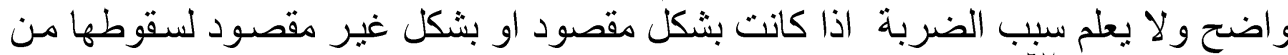

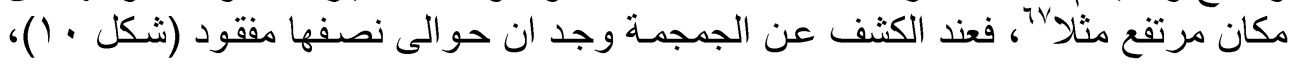




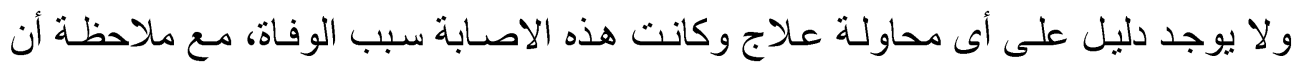

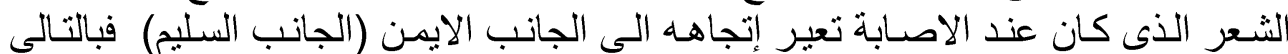

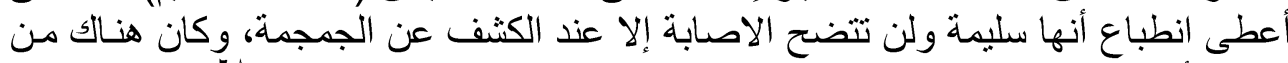

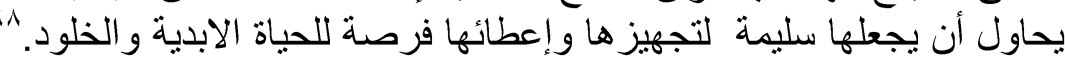

: ثُانياً: HK6

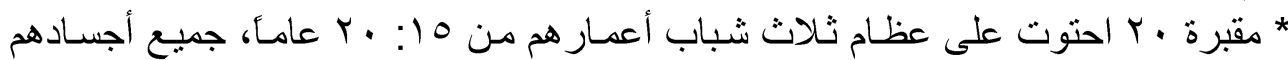

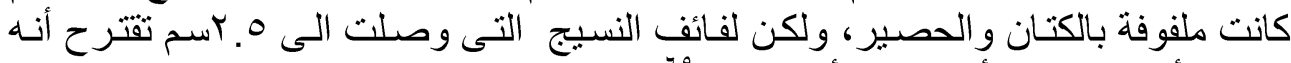

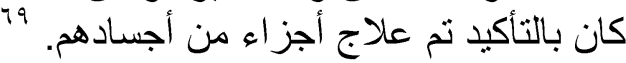

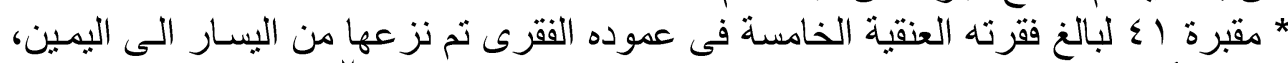

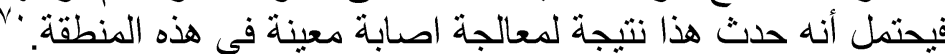

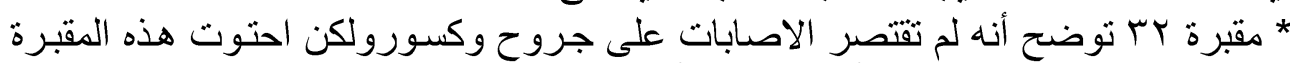

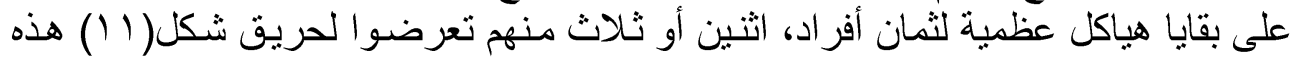

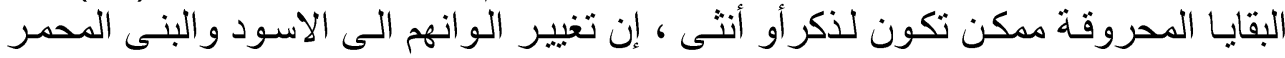

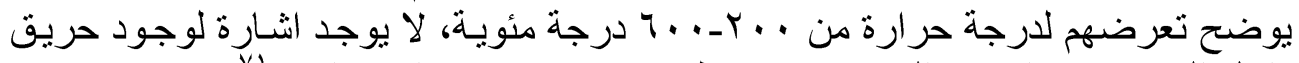

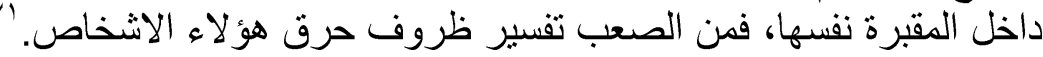

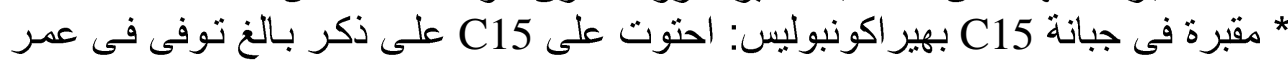

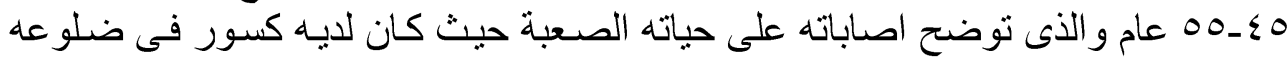

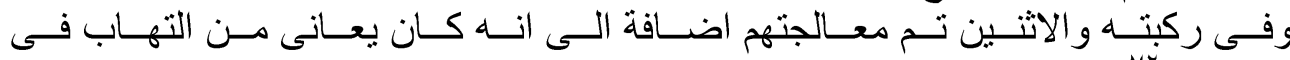

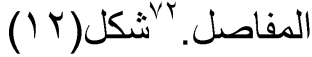

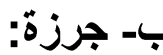

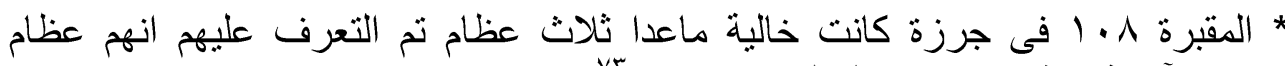

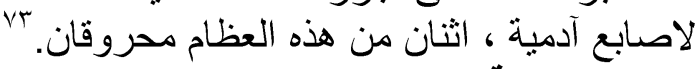

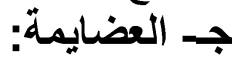

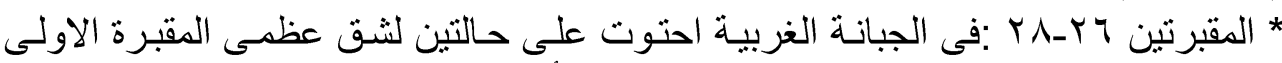

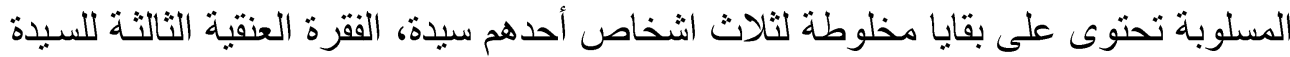

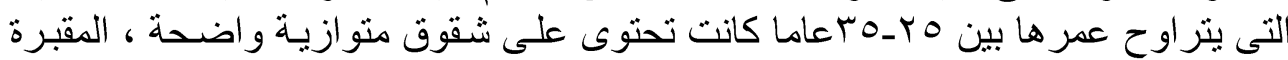

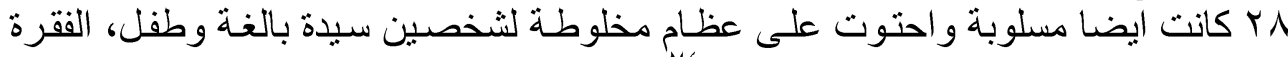

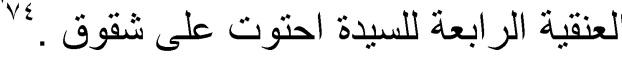
د- جبل نبتة - جيل العة الرملة:

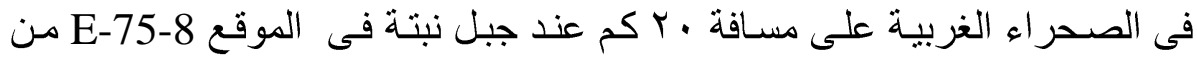

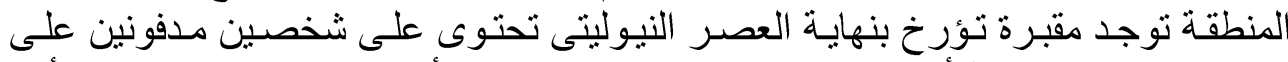

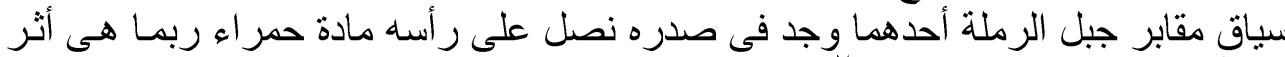

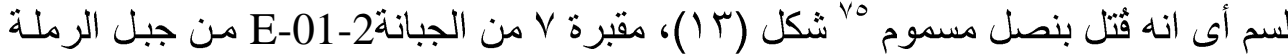

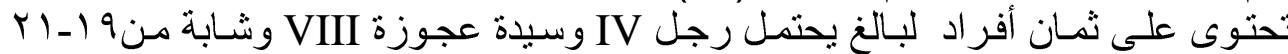

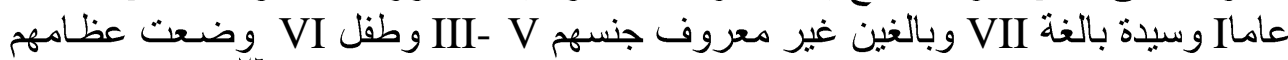

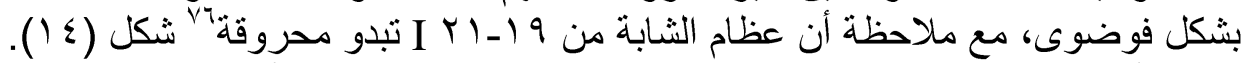

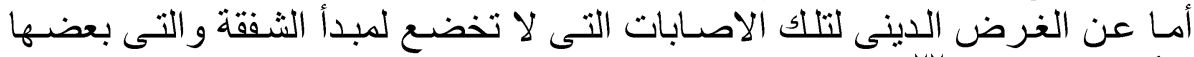

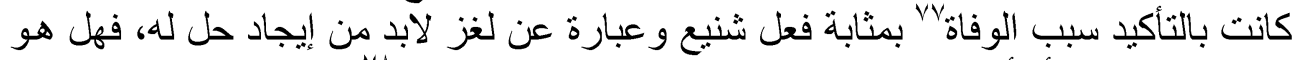

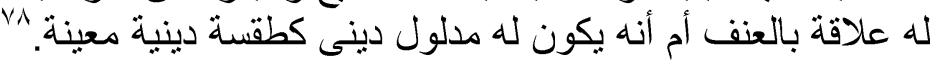




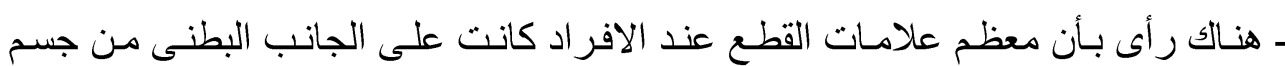

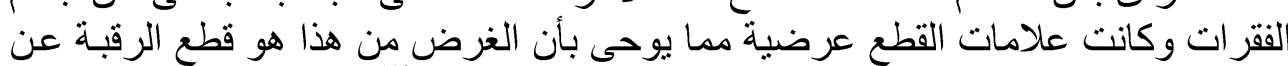

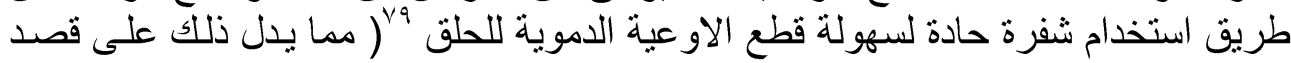

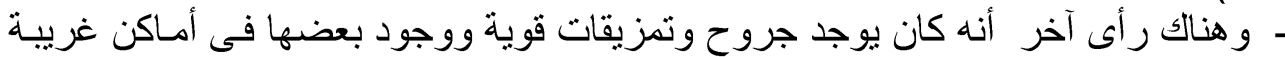

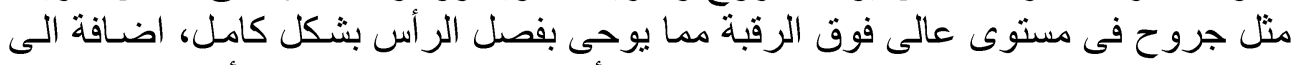

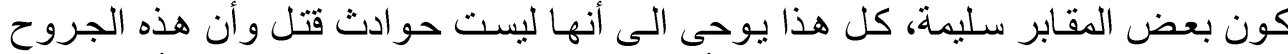

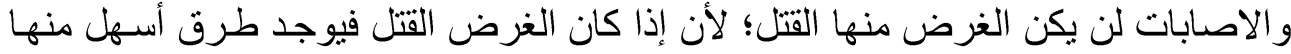

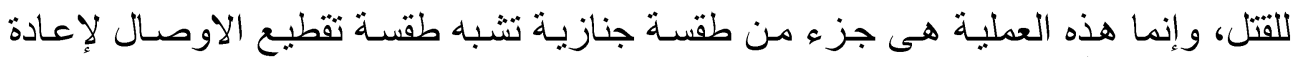

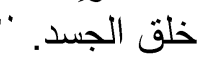
ـ كانت القطوع فى الققرات العنقية تشبه الخدوش الخفيفة حول الققرة وهى عديدة المرات

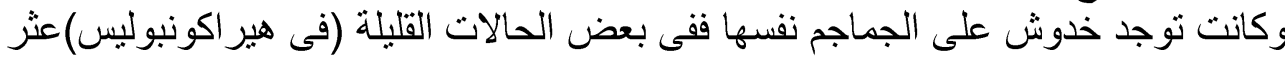

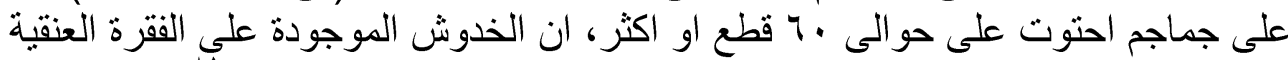

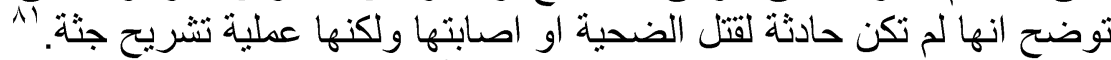
ـ بعض المقابر كانت الاصدابة التى تعرض لها لها أصحابها هى الحريق، فطبقأ لما اعتدنا عليه

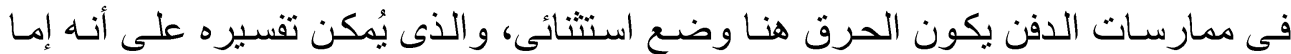

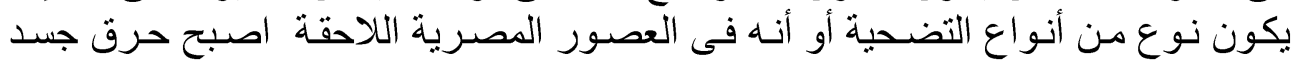

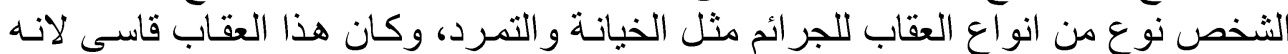

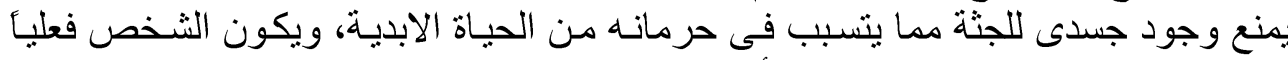

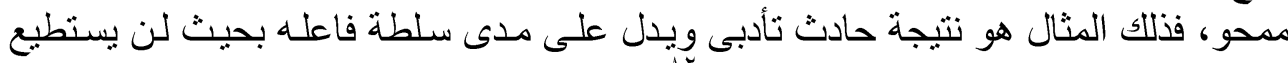

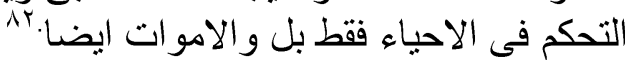

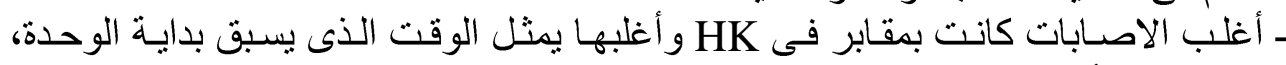

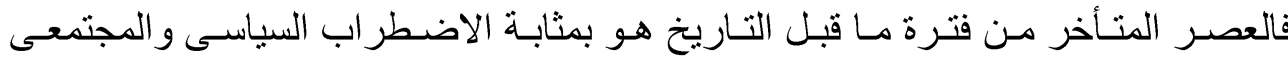

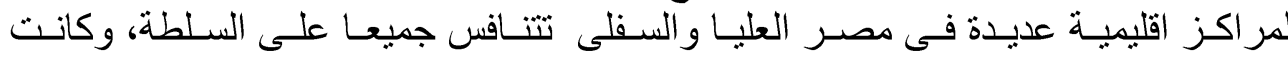

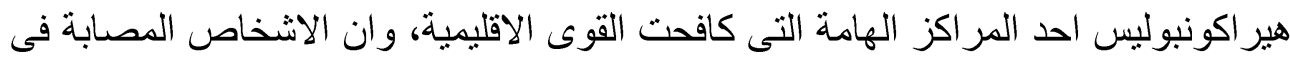

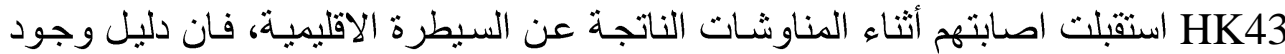

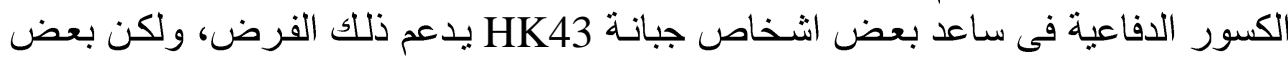

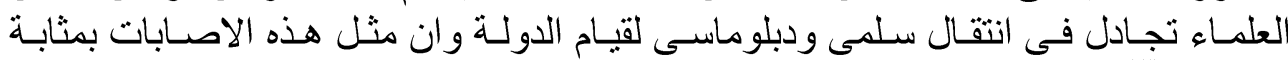

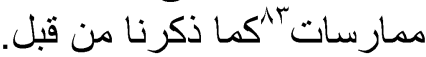
ـ احتوت اغلب مقابر العمال فئ

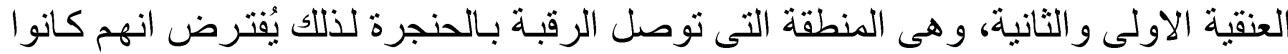

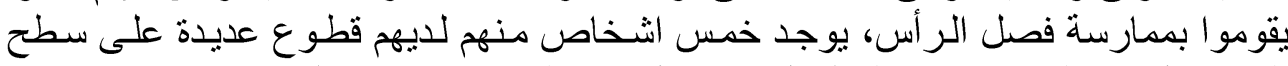

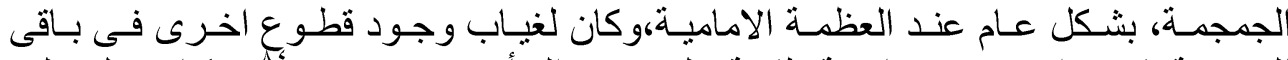

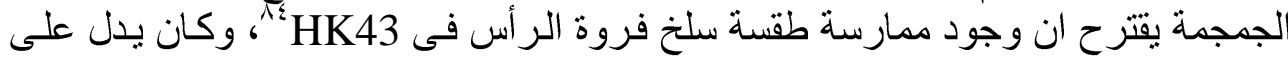

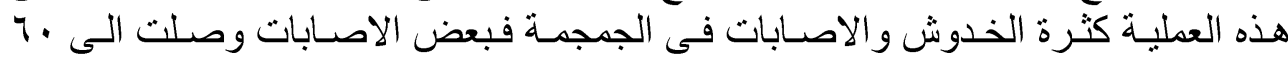

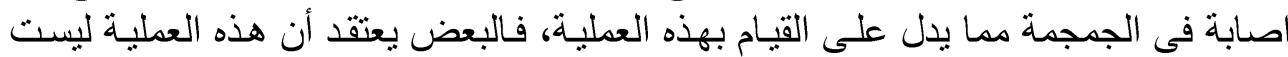

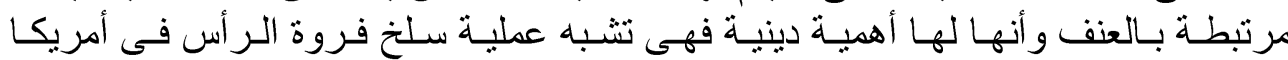

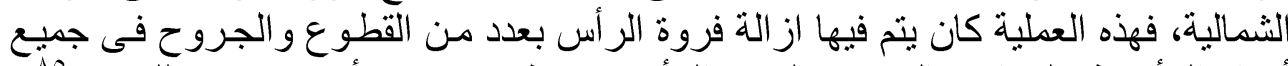

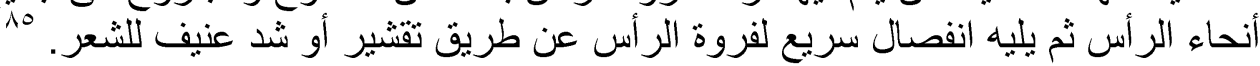




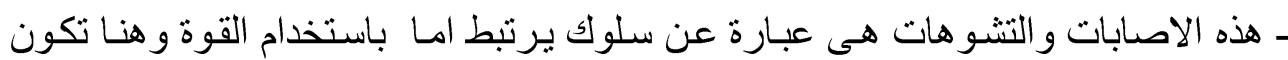

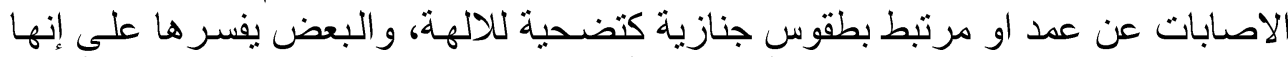

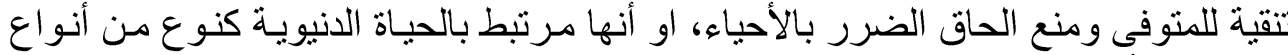

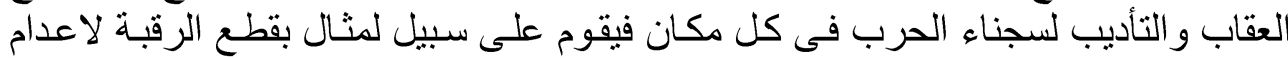

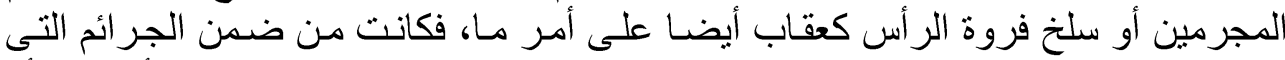

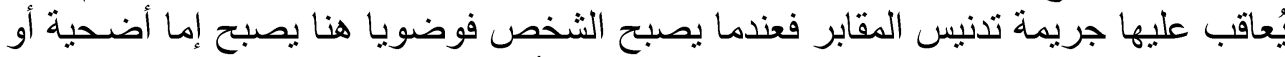

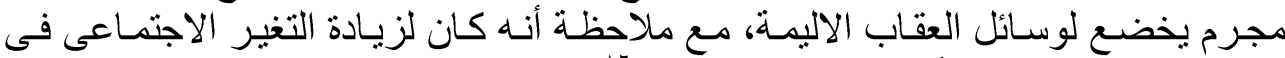

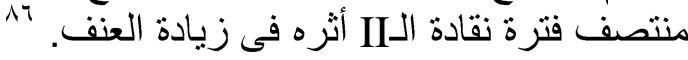

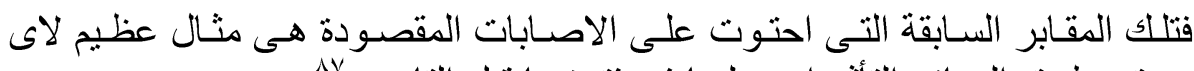

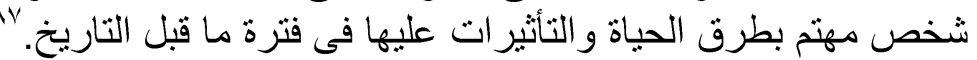

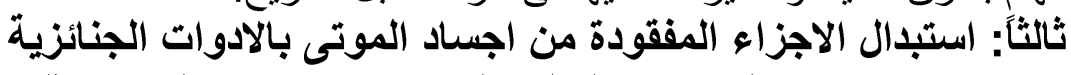

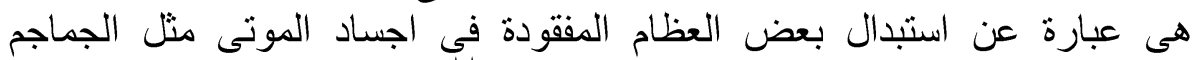

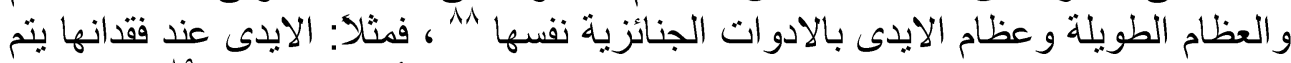

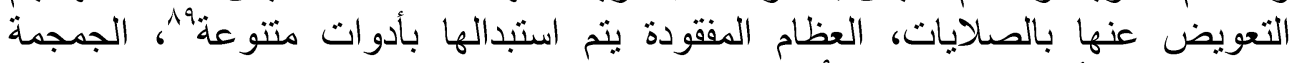

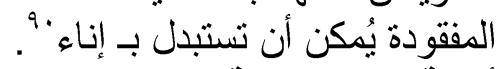

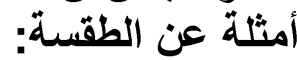

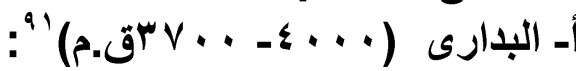

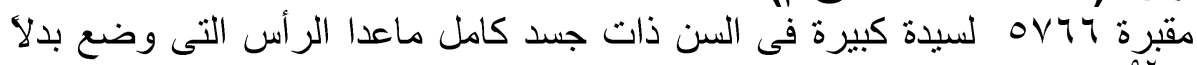

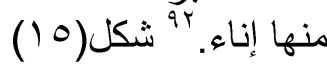

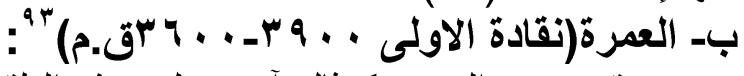

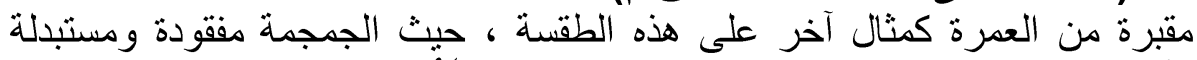

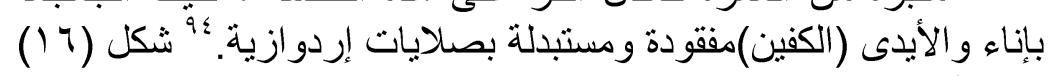

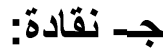

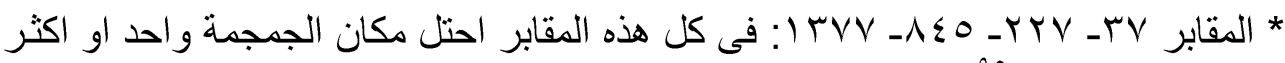

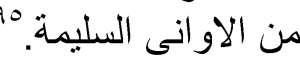

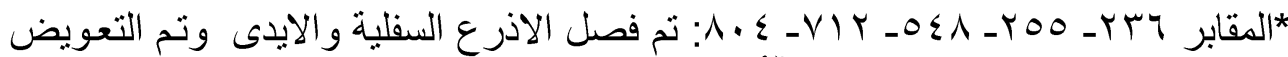

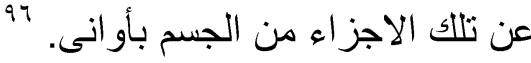

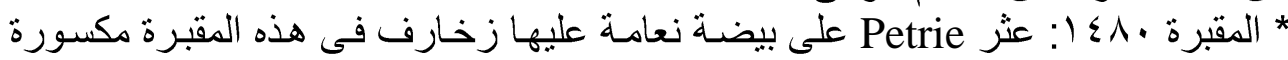

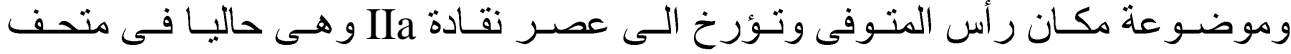

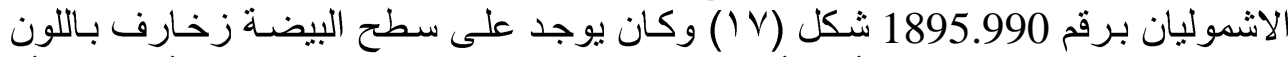

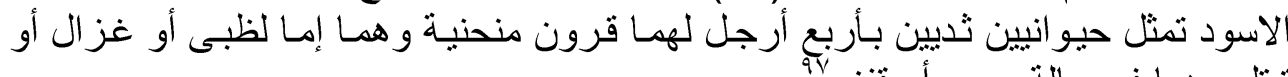

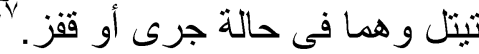

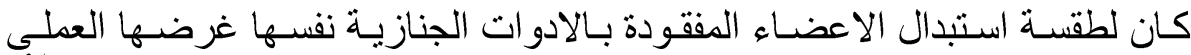

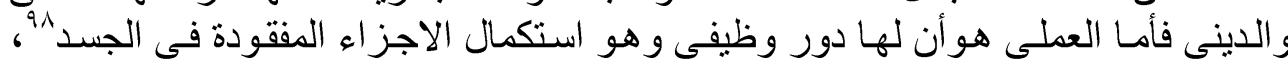

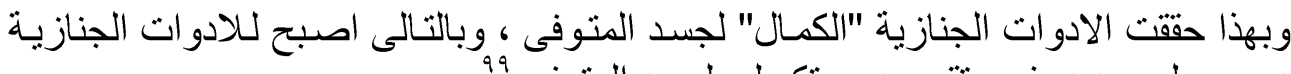

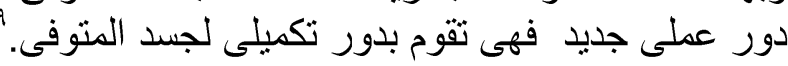

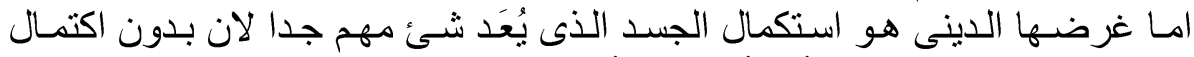

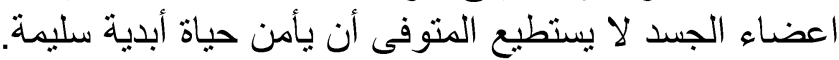

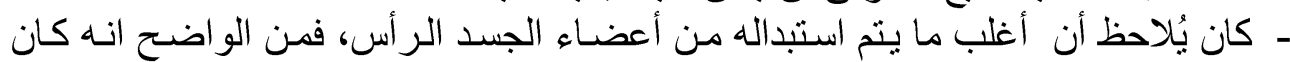

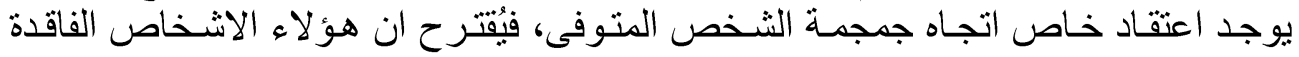




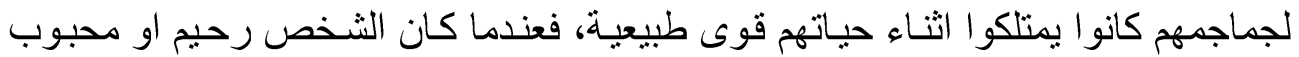

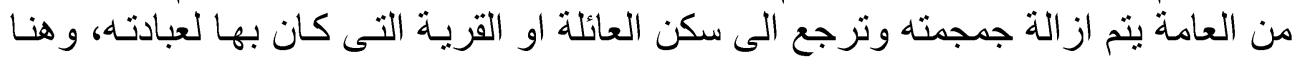

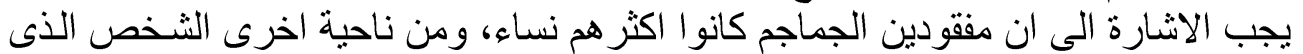

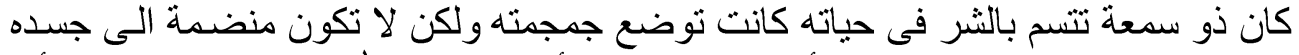

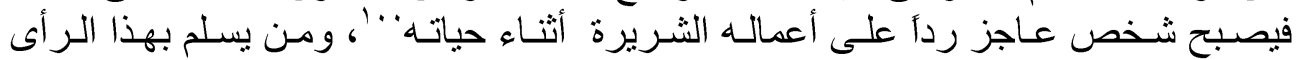

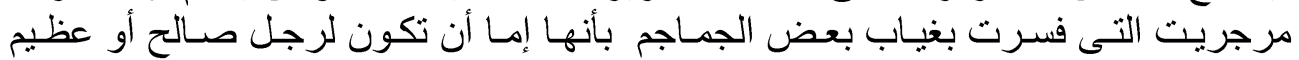

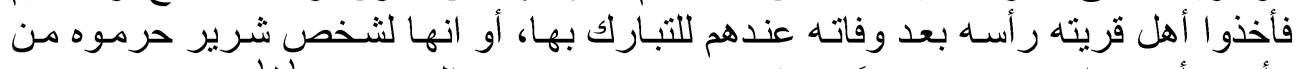

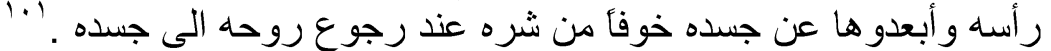

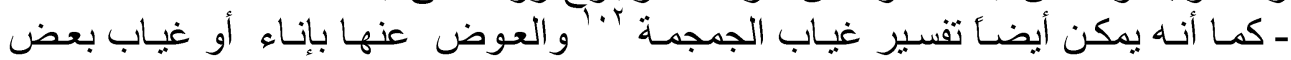

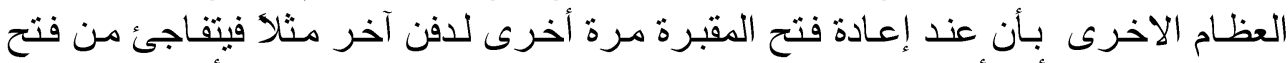

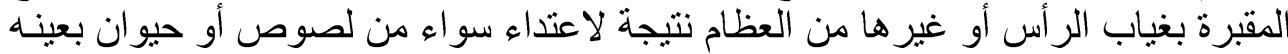

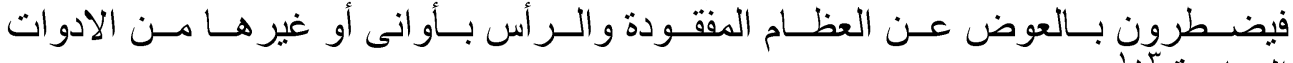

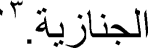

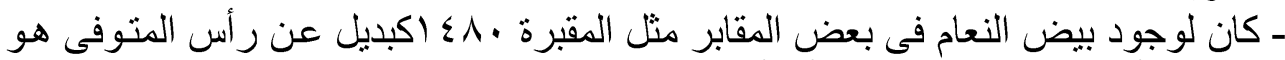

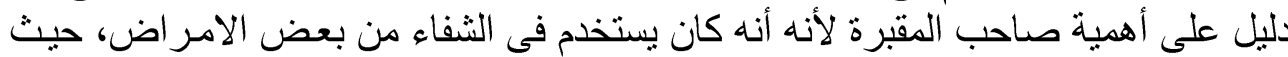
تذكر الوصفة 1 الج من بردية ايبرس: phrt nt sm3 hft bi3 n Šndt rdi hr mw m niw s dr grḥ mhyt dw3.k r hbk st $m$ mh $n$ inr $r$ sgm.k st sinw swt r rdi.f r s3 swr.f st عـاج لقتل الثعبان hf

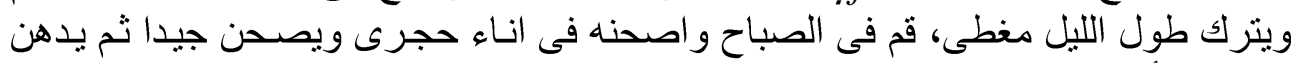

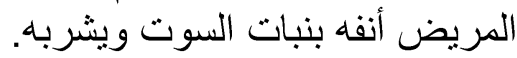

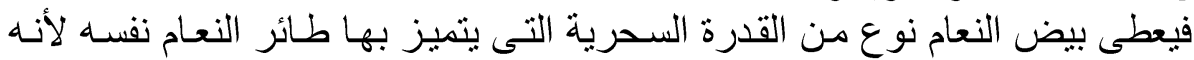

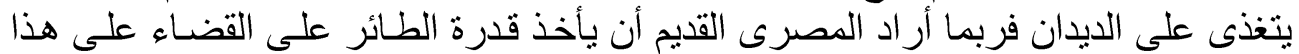

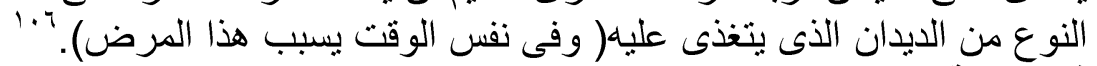

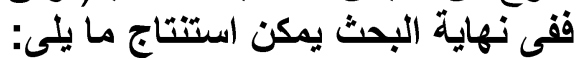

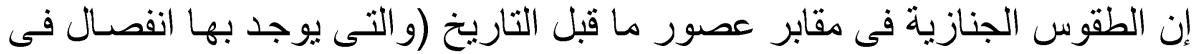

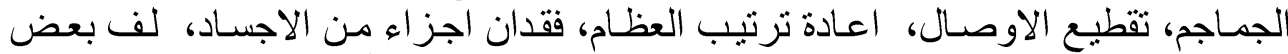

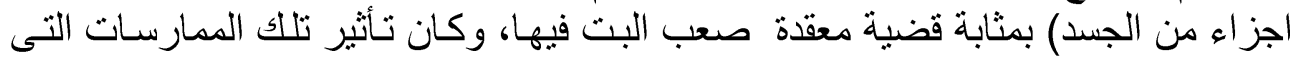

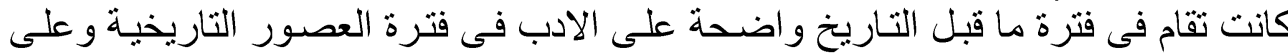

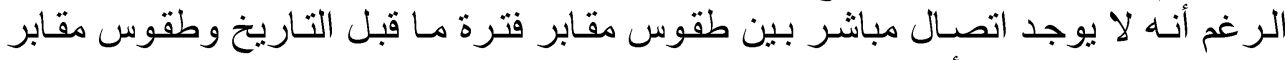

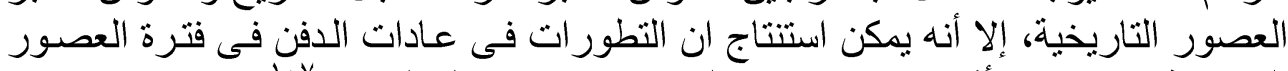

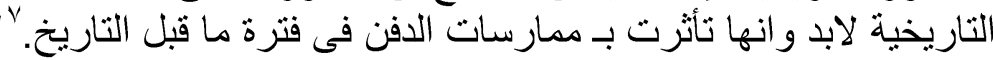

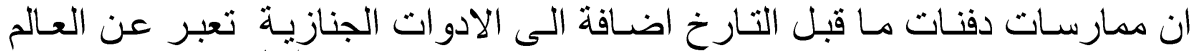

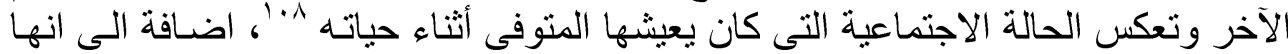

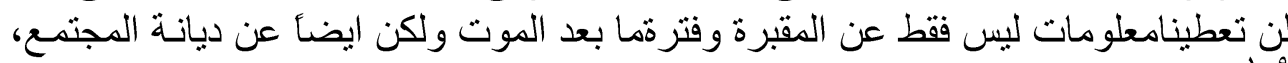

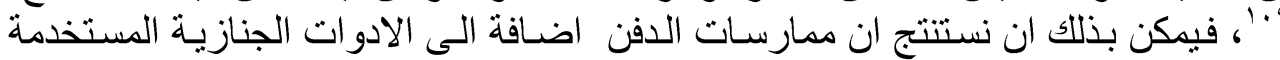

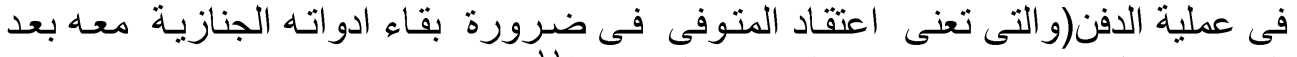
الموت) تعطى صورة عن حياة الثخص الثن المدفون. 


\section{الاشكال}

$$
\text { أو هلاً:تقطيع أوصال الموتى }
$$

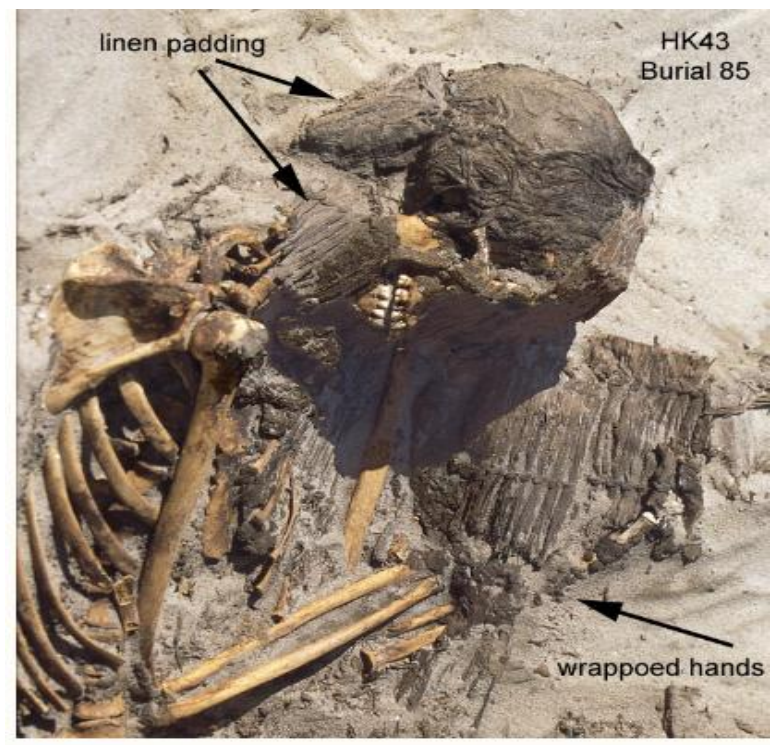

شكل( (1)

مقبرة لسيدة 10 فى HK43 و التى رقبتها ويديها مقطو عتان وملفوفتان بالكتان. نقلا عن:

http:// www. hierakonpolis-online.org/index.php/explore-thepredynastic-cemeteries/hk43-workers-cemeter

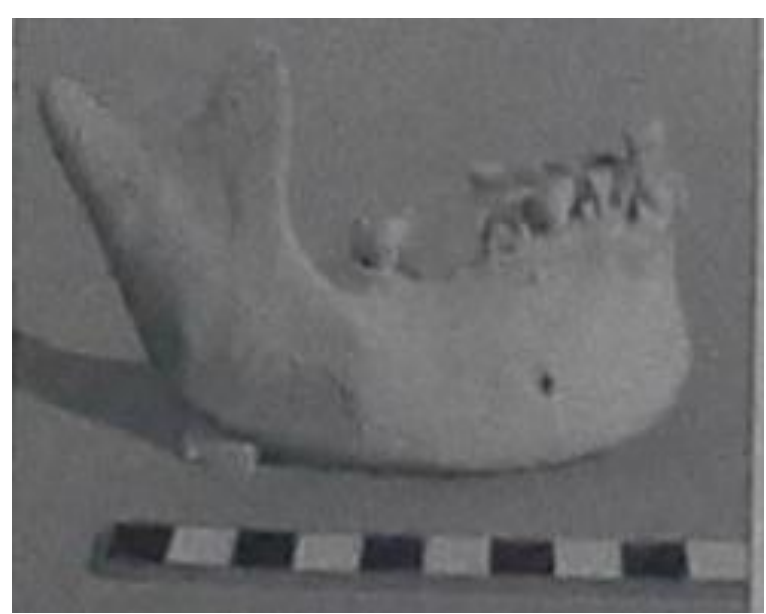

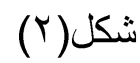

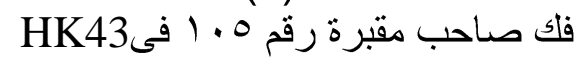
نقلا عن:

S. P. DOUGHERTY, "The lost tombs of F.W.GREEN", Nekhen News15(2003), p.24 


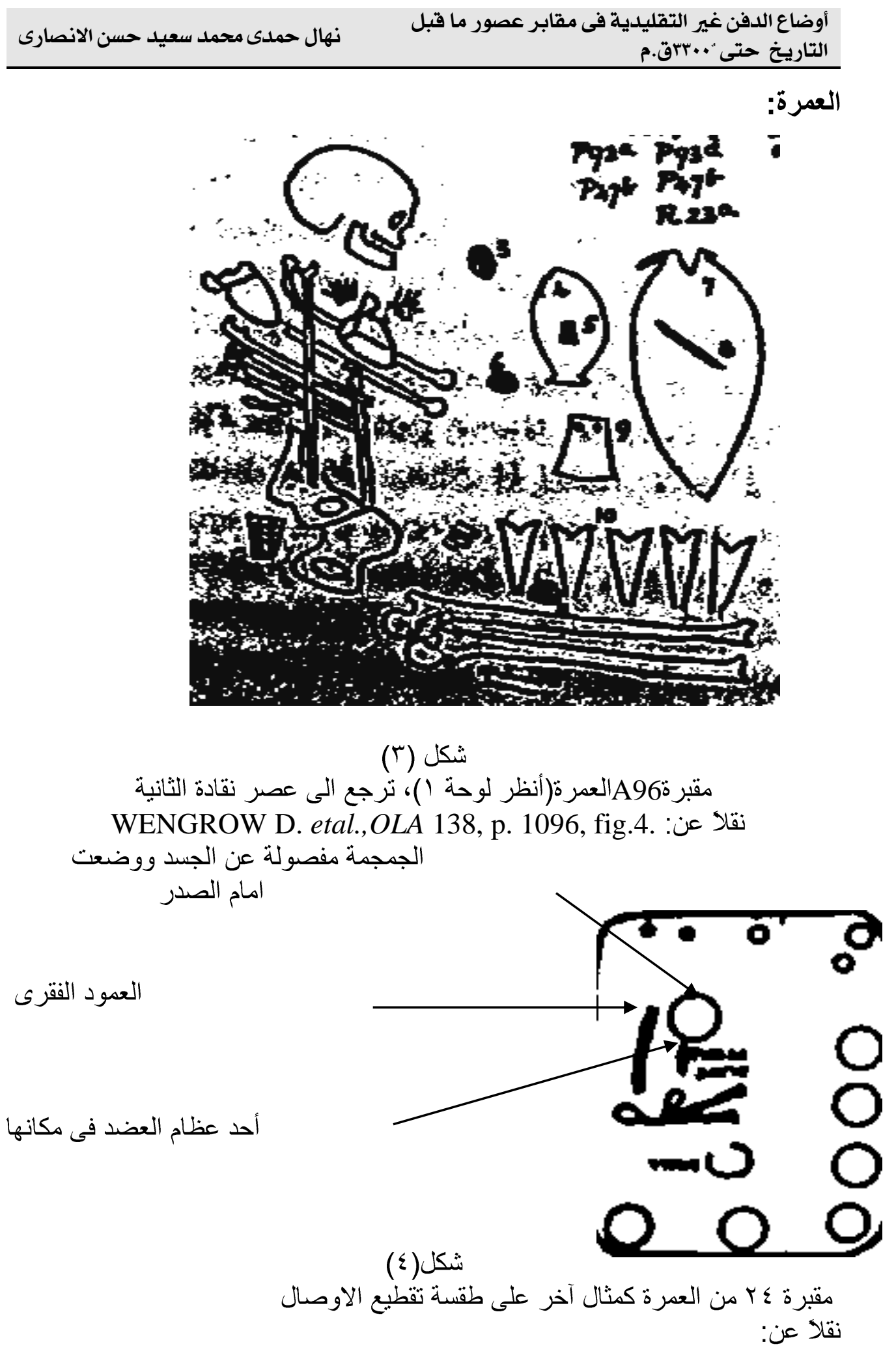

M. A. MURRAY, "Burial Customs and Beliefs in the Hereafter in Predynastic Egypt", JEA 41, fig. 4 


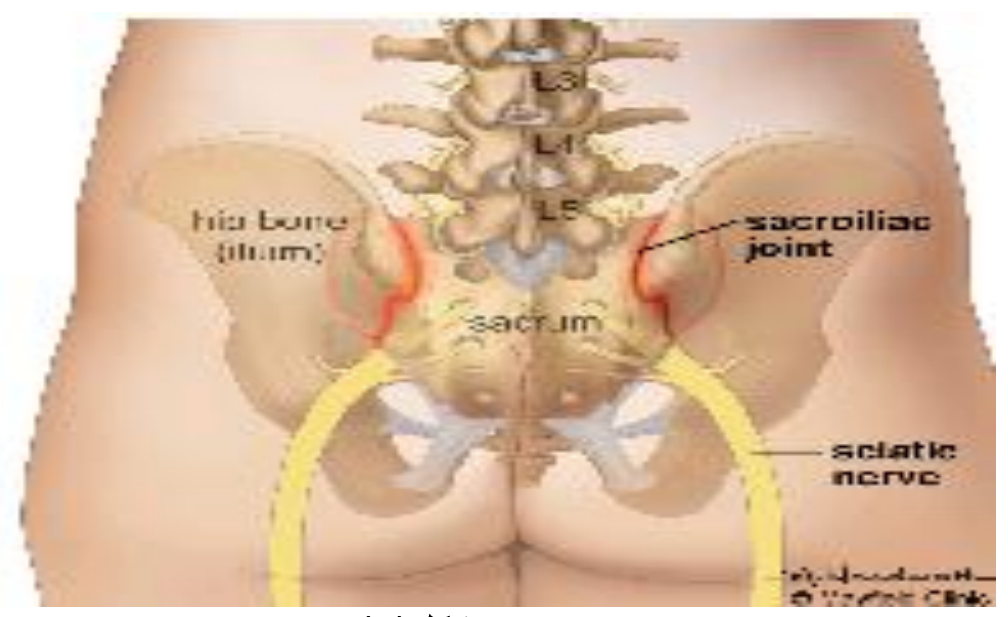

شكل(0)

كظم العجز Sacrum

نقلا عن:

www. Mayfieldclinic.com
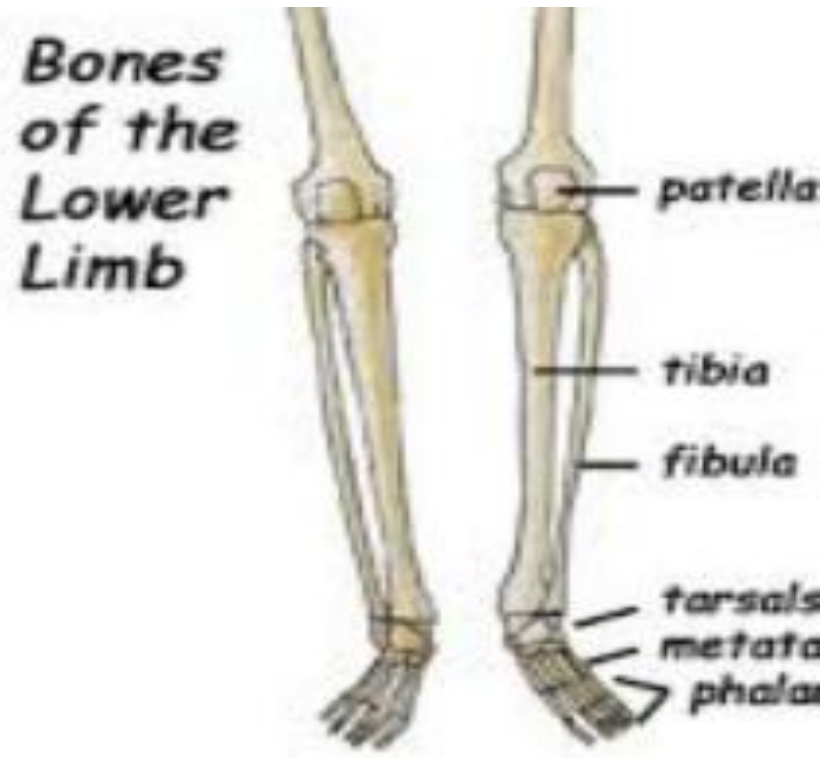

شكل(7)

fibulae و الثظية tibiae عظام القصبة

نقلا عن:

www. susaningraham.net/leg-bones.htmt 


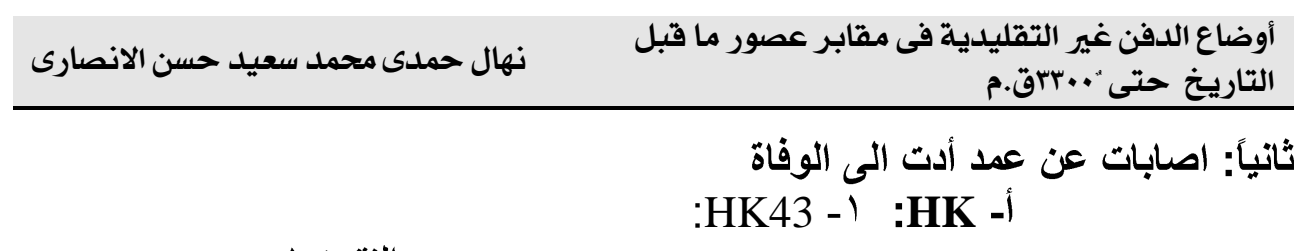

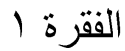

الققرة العنقية الثانية مكان الاصابة

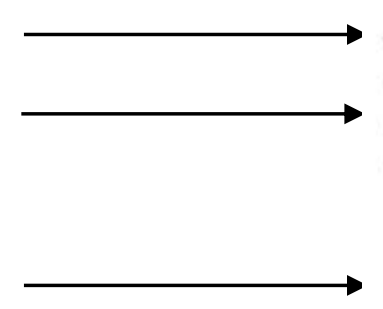

الفقرة V

شكل(V)

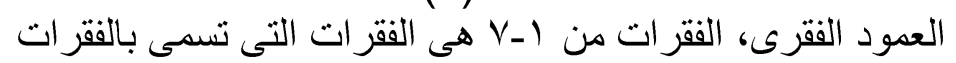

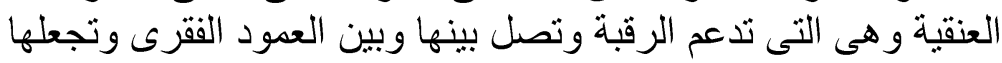

$$
\text { نقاء عنا. }
$$

D. ANTOINE, "Pain in the neck? An abnormality from HK27C", Nekhen News22(2010), p.23. 


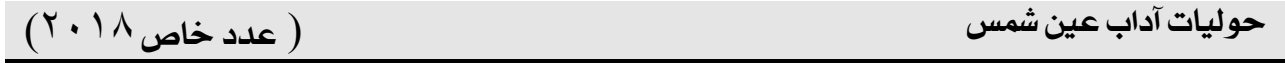

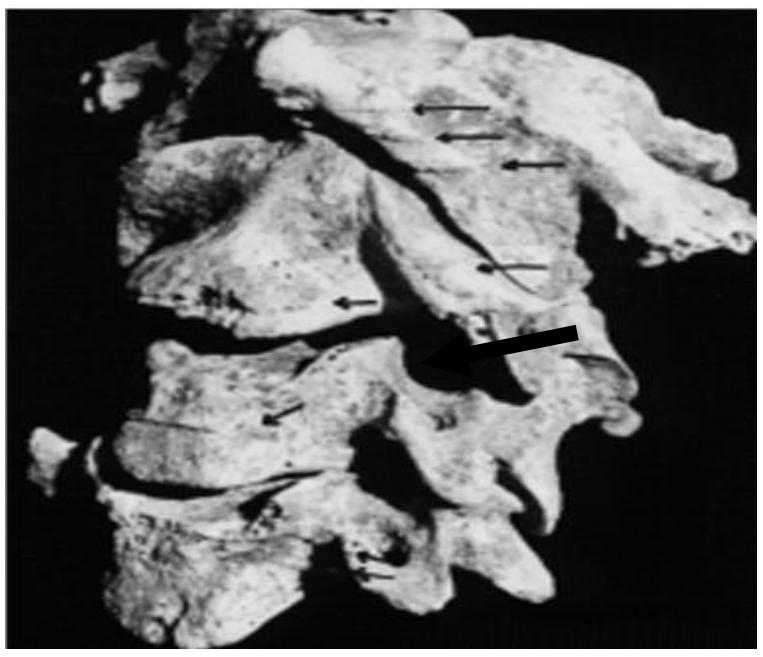

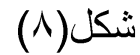

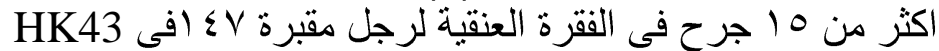

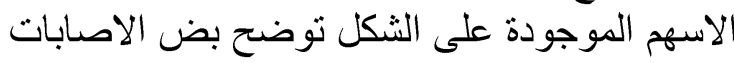
نقلا عن:

MAISH, R. FRIEDMAN, «Pondering Paddy: Unwrapping the mysteries of HK43», Nekhen News11(1999), p.6

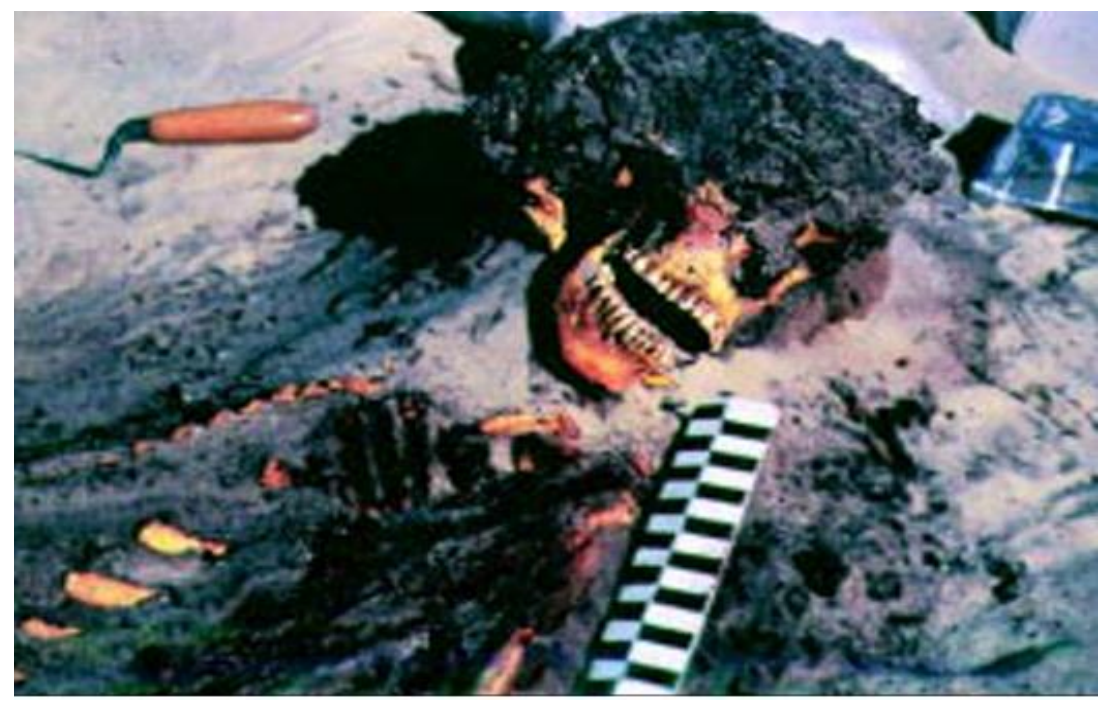

شكل(9) (9) (9)

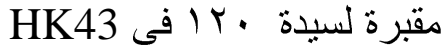

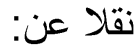

FRIEDMAN R. F. etals., "Preliminary report on field work at Hierakonpolis: 1996- 1998”, JARC 36, 1999, p. 11, fig. 10 


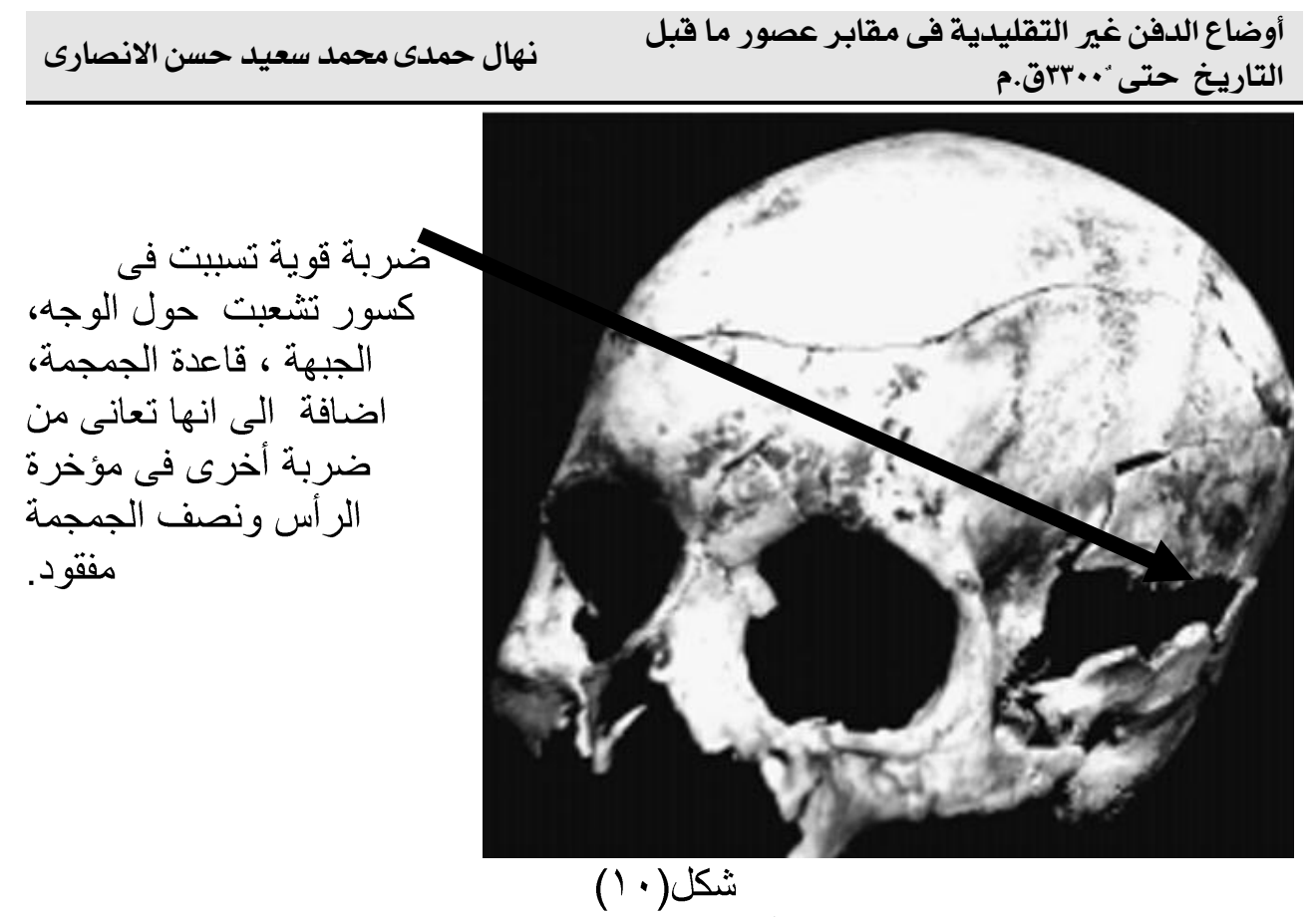

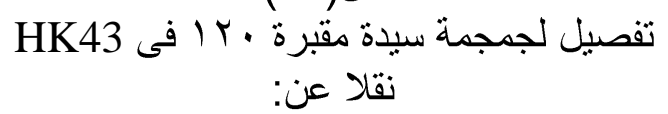

A. MAISH, «Trauma at HK43», Nekhen News10(1998), p. 7.

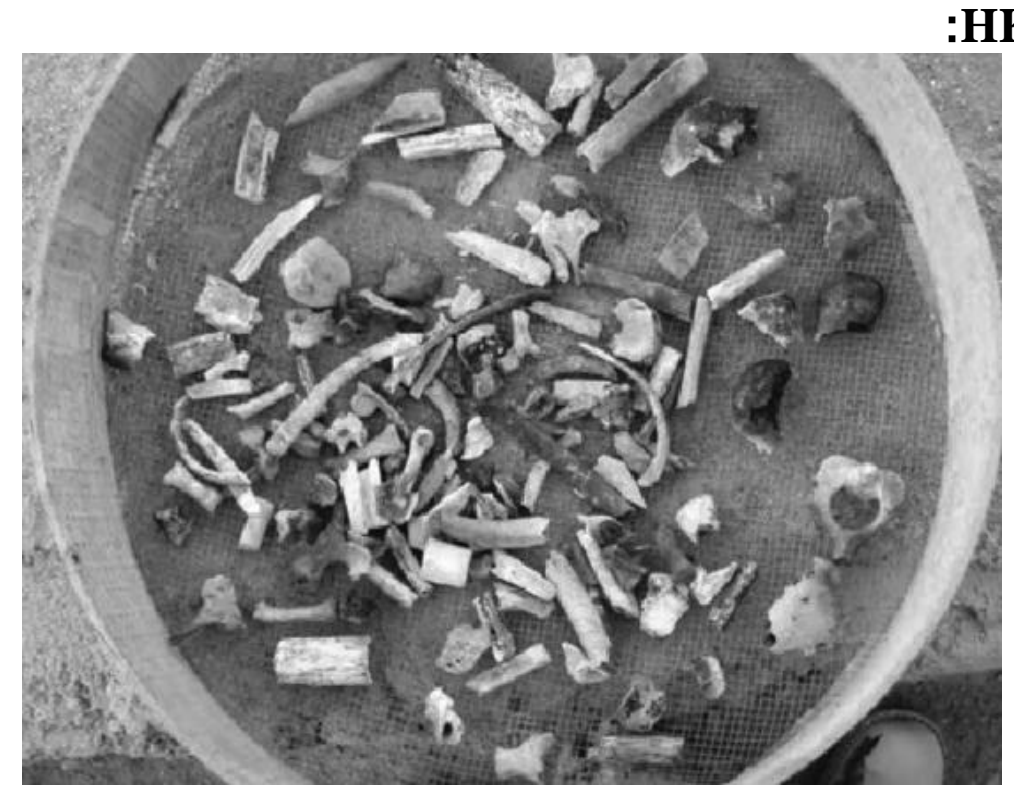

شكل(1) (1)

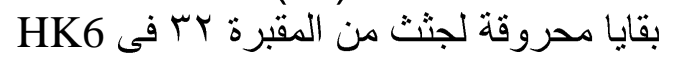

نقلا عن:

S. P. DOUGHERTY, "Death in fragments: piecing together the skeletons of HK6" Nekhen News22(2010), p.7. 


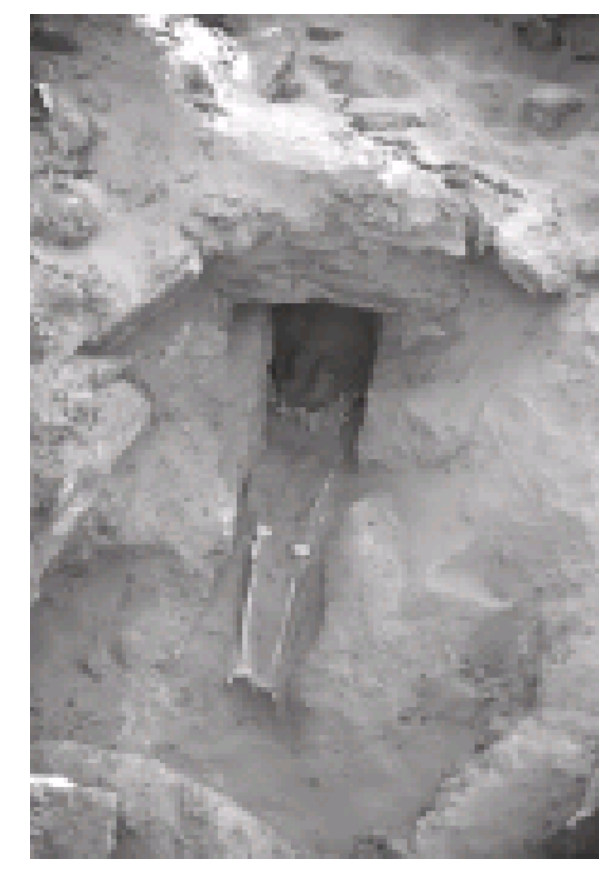

شكل(r) (1) (1)

مقبرة C15 في ركام هير اكونبوليس

نقلا عن:

L. RAISTON, "Exploring the Secret of the Gebel", Nekhen News14(2002), p.19.

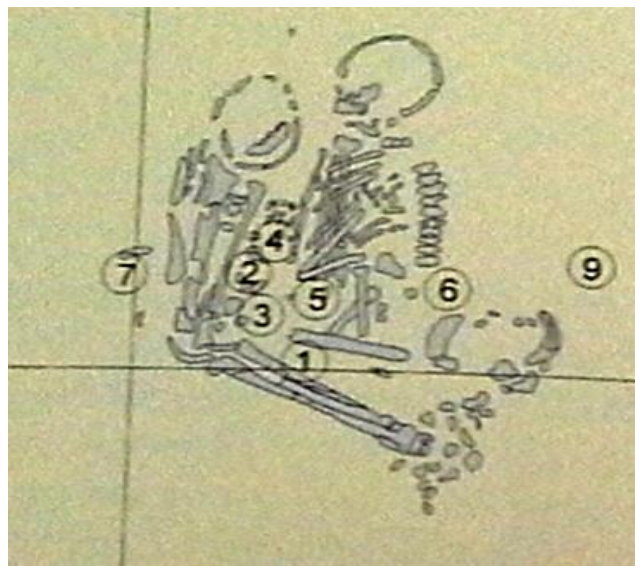

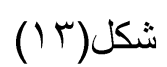

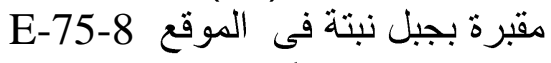

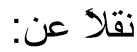

M. KOBUSIEWICZ, J. KABACIŃSKI, "Cemeteries", Gebel Ramlah, Institute of Archaeology and Ethnology Polish Academy of Sciences Poznań Branch, 2010, p. 252, fig. 8.1 

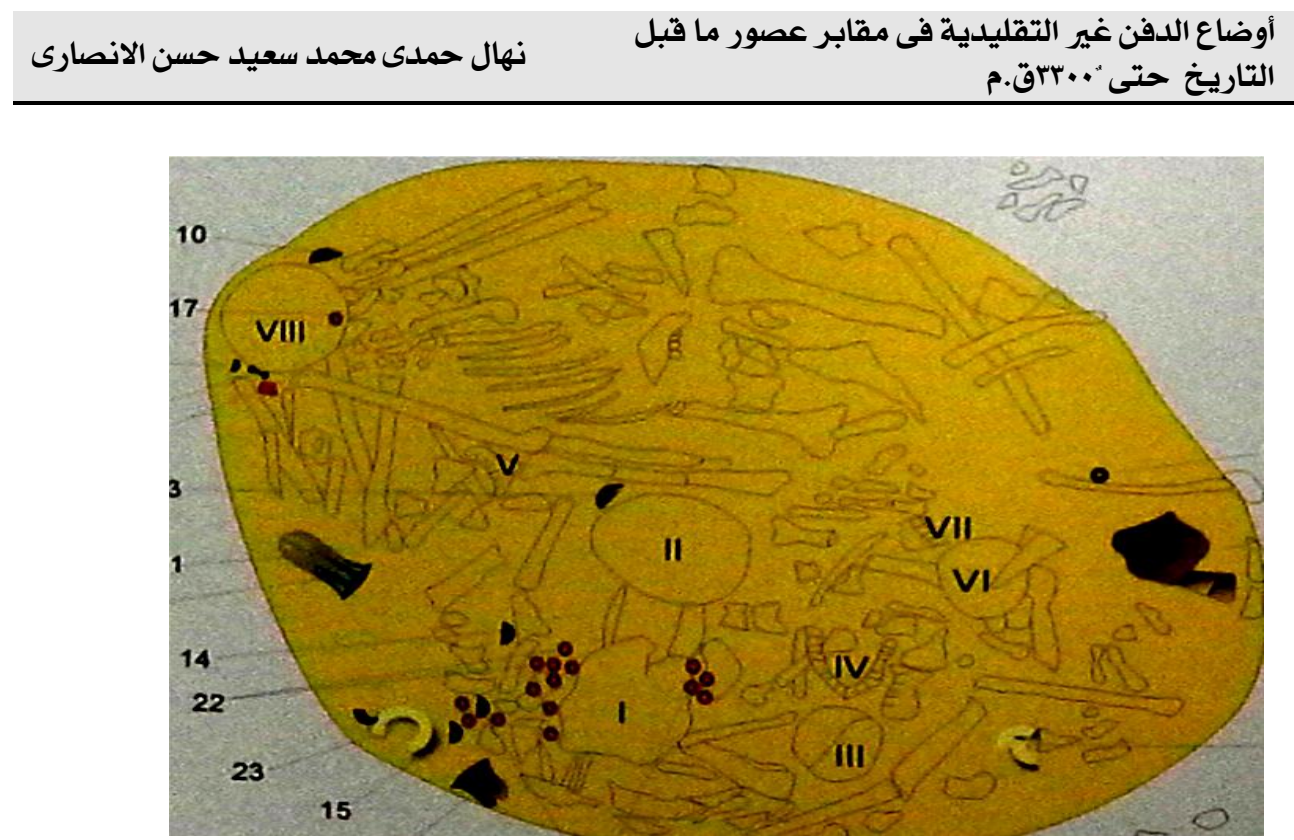

$$
\text { المقبرة v فى الجبانة) }
$$

M. KOBUSIEWICZ, J. KABACIŃSKI, "Cemeteries", Gebel Ramlah, Institute of Archaeology and Ethnology Polish Academy of Sciences Poznań Branch, 2010, p. 32, fig. 1.26

ثالثًا: استبدال الاجزاء المفقودة من اجساد الموتى بالادوات الجنائزية

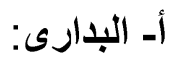

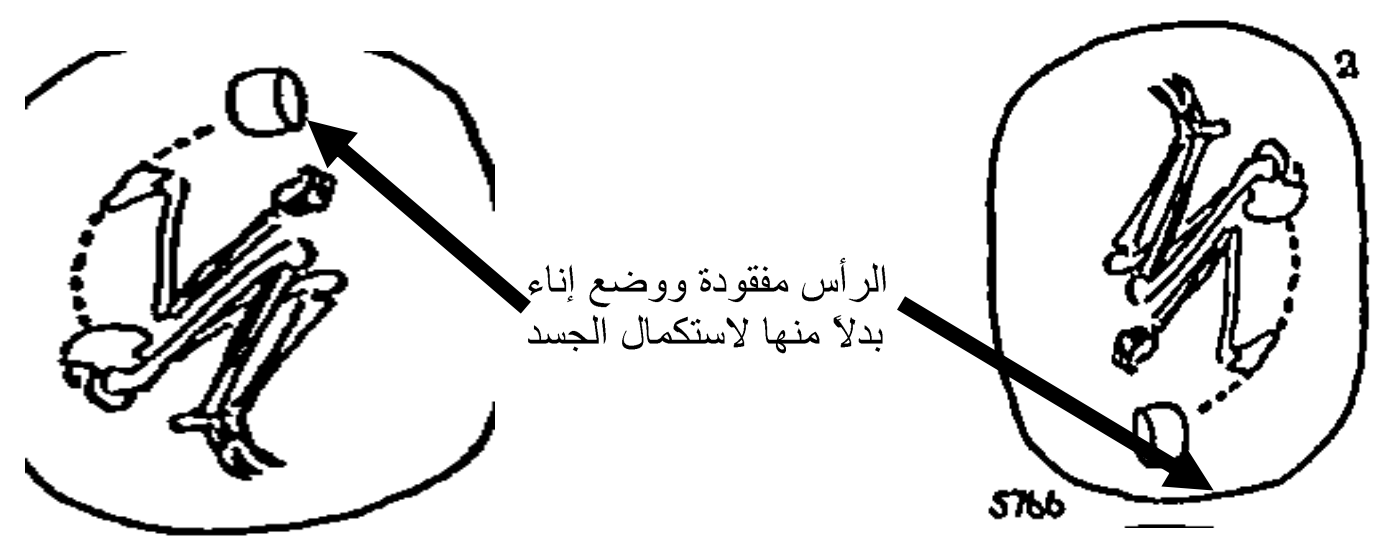

شكل (10)

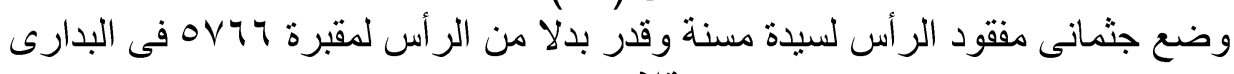

نقلا عن:

M. A. MURRAY, "Burial Customs and Beliefs in the Hereafter in Predynastic Egypt", JEA 41, fig. 2 
جمجمة مفقودة ومستبدلة بإناء

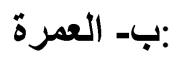

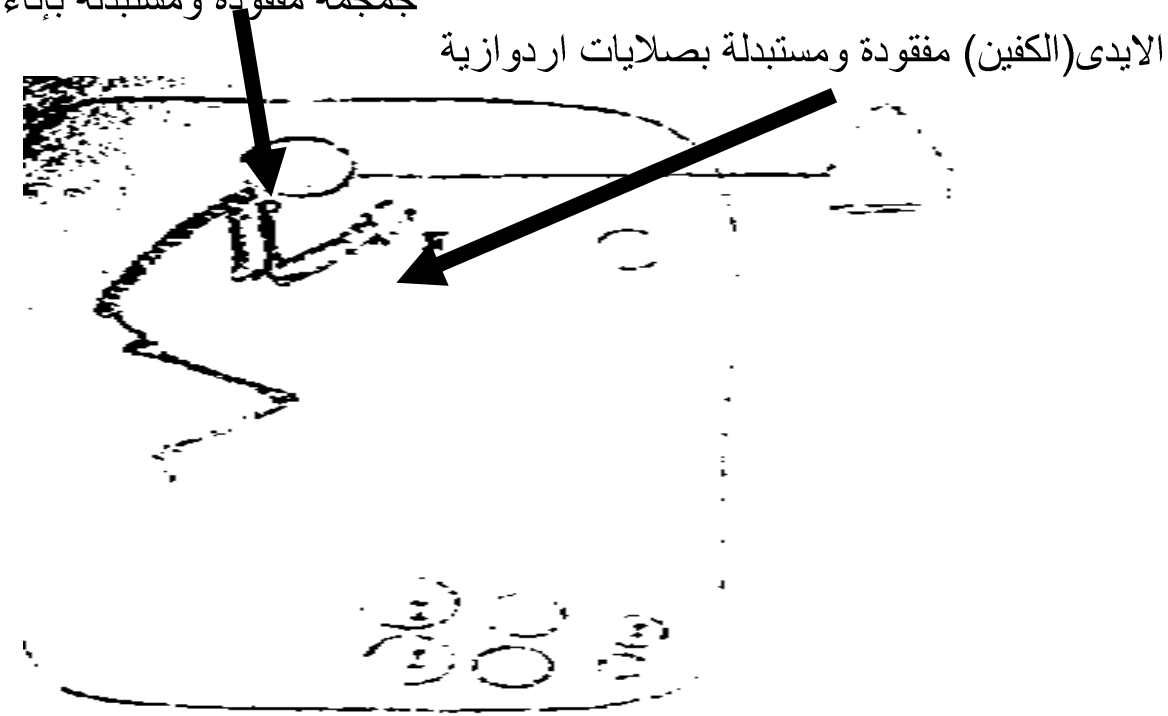

شكل(7 ( )

مقبرة من العمرة مثال على عملية استبدال العظام والاجز اء المفقودة بـ الادوات الجنائزية نقلا عن:

VALTORTA E., "The ritualised body”, in: J. P. GRZYBOWSKA eds., The Pultusk Academy of Humanities, V.II, 2009, p.199, fig. 1.

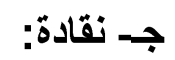

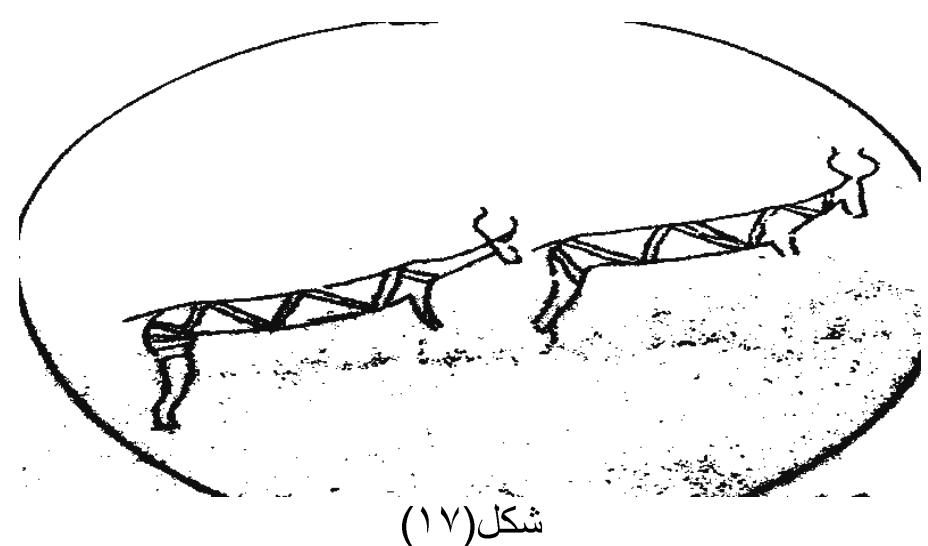

بيضة نعام وجدها بترى مكان رأس متوفى مقبرة . ــ ا بنقادة ، حاليا بالمتحف الاشمولى

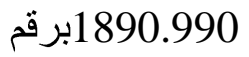

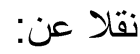

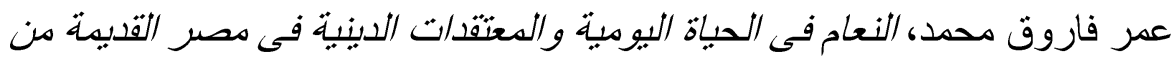

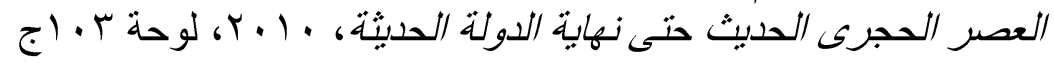




\section{Abstract \\ The exceptional dead positions in pre-dynastic burials in Egypt until 3300BC By Nihal Hamdy}

The search talk about The exceptional dead positions in pre-dynastic burials in Egypt until 3300BC, this burials consist of three groups:

Firstly: Dismemberment

Secondly: direct injuries which were the reason of the death

Thirtly: replace the lost parts of the bodies of the dead with the grave good it self.

The search will explain features of each group and Recognition of religious purpose of these rituals which used in three groups in the tombs.

\section{الهوامش}

1- W. ANDERSON, "Badarian burials: evidence of social inequality in middle Egypt during the early predynastic era", JARC 29, p.51- 53.

r- نم الوصول الى هذا التقسيم بعد الاطلاع على هذه المقالة:

VALTORTA E., "The ritualised body:", in: J. P. GRZYBOWSKA eds., The Pultusk Academy of Humanities. Acta Archaeologica Pultuskiensia, V.II, 2009, pp.195-205.

3- VALTORTA E., "The ritualised body", in: GRZYBOWSKA J. P. eds., The Pultusk Academy of Humanities. Acta Archaeologica Pultuskiensia, V.II, 2009, pp.204-205.

4- FRIEDMAN R. etals., "Excavations at Hierakonpolis", Archéo Nil 12, 2002, p. 65.

5- HASSAN F. A., ,OLA 138, 2004, p. 780- 782.

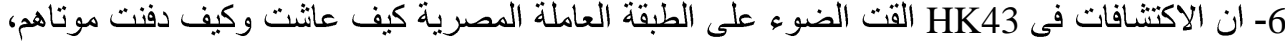

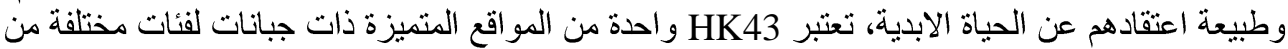

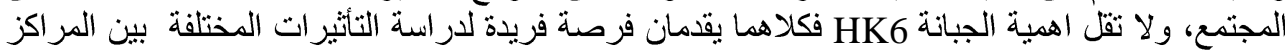

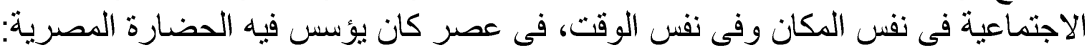
FRIEDMAN R. etals., "Excavations at Hierakonpolis", Archéo Nil 12, 2002, p. 65-67.

7- A. MAISH, R. FRIEDMAN, «Pondering Paddy: Unwrapping the mysteries of HK43», Nekhen News11(1999), p.6.

8- HASSAN F. A., "Between man and goddess: the fear of nothingness \& dismemberment", in HENDRICKX S. eds., Egypt at its origins. Studies in memory of ADAMS B. ,OLA 138, 2004, p. 780- 782 .

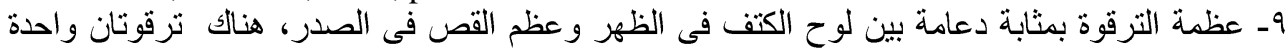

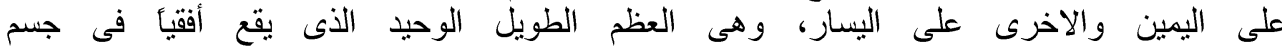
الانسان:الئن/2ttps://ar.wikipedia.org/wiki

10- S. P. DOUGHERTY, "The lost tombs of F.W.GREEN", Nekhen News15(2003), p.24.

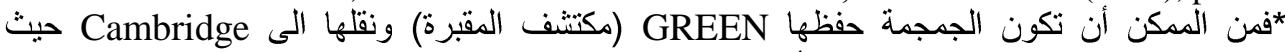

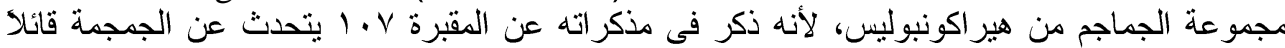

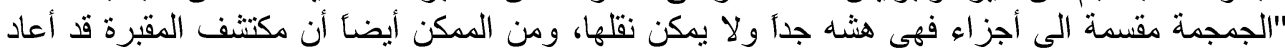

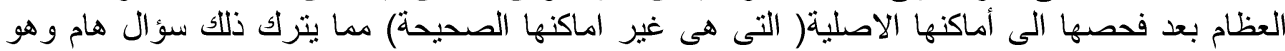

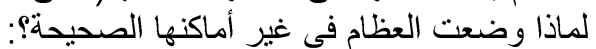

S. P. DOUGHERTY, "The lost tombs of F.W.GREEN", Nekhen News15(2003), p.24.

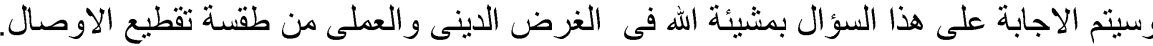

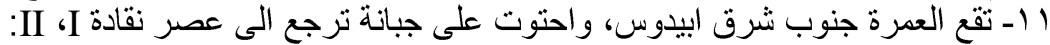

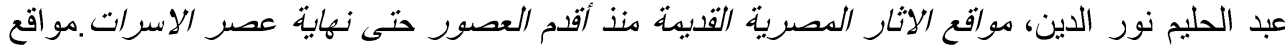

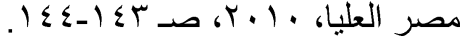

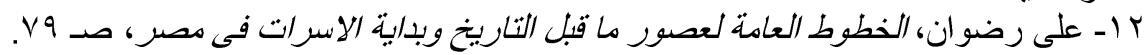

13- D. WENGROW etal., "Images human bodies and the ritual construction of memory in 
late predynastic Egypt”, in S. HENDRICKX eds., Egypt at its origins. Studies in memory of B. ADAMS, OLA 138, p. 1095

14- M. A. MURRAY, "Burial Customs and Beliefs in the Hereafter in Predynastic Egypt", JEA 41, p. 90.

15-Ipid

16-Ipid

17- TAMORRI V., "The manipulation of human remains in Predynastic Egypt: preliminary observations", in HORN M. eds., Current Research in Egyptology 2010. Proceedings of the eleventh annual symposium leiden University 2010, 2010, p.177.

18- TAMORRI V., op.cit, p.178.

19- Ipid.

• r ـ على رضوان، الخطوط العامة لعصور ما قبل التاريخ وبداية الاسرات فى مصر ، صـ9 V. 21-M. A. MURRAY, JEA 41, p. 93-94.

22- Ipid.

23- Ipid.

24- Ipid.

25- وهى عظمة كبيرة ومنلثة فى قاعدة العمود الققرى فهى الجزء الخلفى لتجويف الحوض:

(https://en.wikipedia.org/wiki/Sacrum)

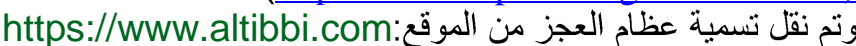

26- المفصل العجزى الحرقفى يقع عند اتصال الجزء الاسفل من العمود الفقرى(المعروف بالققرات

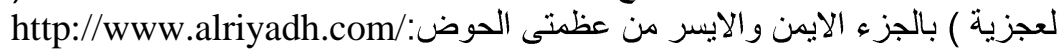

27- M. A. MURRAY, op.cit, p. 93-94.

28- Ipid.

29- Ipid.

30- Ipid.

اس- (عظمتين كبار فى اسفل الساق او الجزء الاسفل من الساق الخلفية)و Fibulae (عظمتين الخارجتين

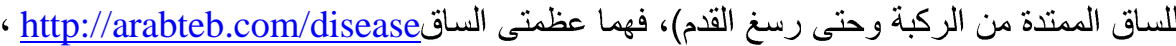

مرن

32- M. A. MURRAY, op.cit, p. 93-94.

من الموقع:https://ar.wikipedia.org/wiki

33- Ipid

34- TAMORRI V., "The manipulation of human remains in Predynastic Egypt: preliminary observations", in HORN M. eds., Current Research in Egyptology 2010. Proceedings of the eleventh annual symposium leiden University 2010, 2010, pp. 203-204.

35- Ipid.

36- TAMORRI V., op.cit, p. 177.

37- WENGROW D., BAINES J., "Images, Human bodies and the ritual construction of memory in late Predynastic Egypt", in HENDRICKX S. eds., Egypt at its origins. Studies in memory of ADAMS B., OLA 138, p.1098- 1099

يـ- بياتريكس ميدان رينيس، عصور ما قبل التاريخ فى مصر منذ المصربين الاوائل حتى الفراعنة

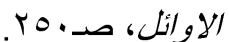

39-M. A. MURRAY, "Burial Customs and Beliefs in the Hereafter in Predynastic Egypt", JEA 41, p. 92.

40- FRIEDMAN R. etals., "Excavations at Hierakonpolis", Archéo Nil 12, 2002, p. 65-67.

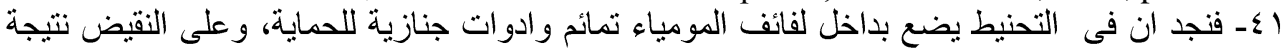

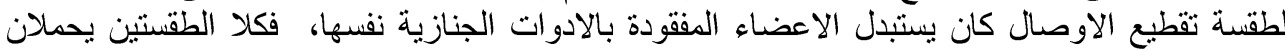

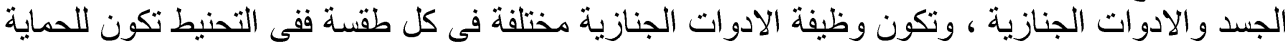
وفى تقطيع الاوصال تكون لاستكمال الجسد ، ونكون

42- WENGROW D., BAINES J., opcit, p. 1105.

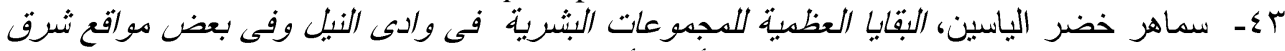

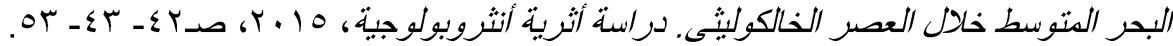




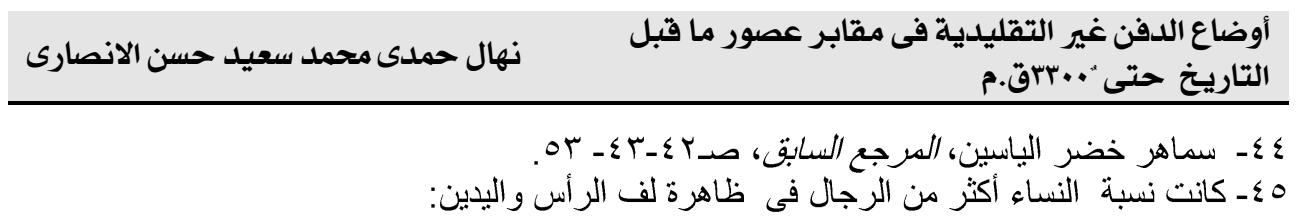

R. FRIEDMAN, «More mummies: The 1998 season at HK43» Nekhen News10(1998), p. 5.

الابدـ فهو معنى رمزى مثل طقسة فتح الفم التى فيها يُثَّار الى حواس الانسان لضمان تفعيلها فى الحياة

47- R. FRIEDMAN, «More mummies: The 1998 season at HK43» Nekhen News10(1998), p. 5.

48- TAMORRI V., "The manipulation of human remains in Predynastic Egypt: preliminary observations", in HORN M. eds., Current Research in Egyptology 2010. Proceedings of the eleventh annual symposium leiden University 2010, 2010, p. 180.

49- WENGROW D., BAINES J., "Images, Human bodies and the ritual construction of memory in late Predynastic Egypt", in HENDRICKX S. eds., Egypt at its origins. Studies in memory of ADAMS B., OLA 138, p.1098- 1099

50- HASSAN F. A., "Between man and goddess: the fear of nothingness \& dismemberment", in HENDRICKX S. eds., Egypt at its origins. Studies in memory of ADAMS B. ,OLA 138, p.792- 795.

51- HASSAN F. A., op.cit, p. 792.

52- HASSAN F. A., op.cit, p. 792- 795.

53- WENGROW D., BAINES J., opcit, p. 1097.

54- ALLEN J. P., The ancient Egyptian Pyramid texts, Writings from the ancient world. Society of biblical literature 23, 2005, p. 83.

55- Wbv, p. 405

56- WbIv, p.590

57- WbI, p. 100

58- WbV, p. 68

59- WbIV, p. 25

60- WbI, p. 170 .

61- SHMAKOV T. T., Critical analysis of J. p. ALLEN's "The ancient Egyptian pyramid texts", p. 212.

62- TAMORRI V., in HORN M. eds., Current Research in Egyptology 2010. Proceedings of the eleventh annual symposium leiden University 2010, 2010, pp. 201-202.

بآ- الفقرات العنقية هى الفقرات التى تتألف منها الرقبة ووجود خدوش أو اصابات بها يدل على محاولة

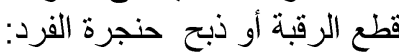

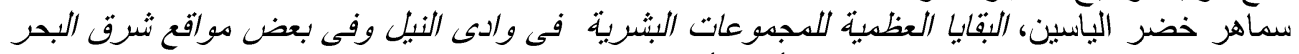

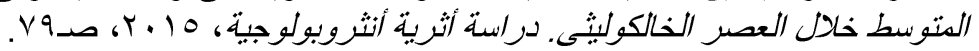

64- FRIEDMAN R. etals., "Excavations at Hierakonpolis", Archéo Nil 12, p.63, 65.

65- Ipid.

66- A. MAISH, R. FRIEDMAN, «Pondering Paddy: Unwrapping the mysteries of HK43», Nekhen News11(1999),p. 6.

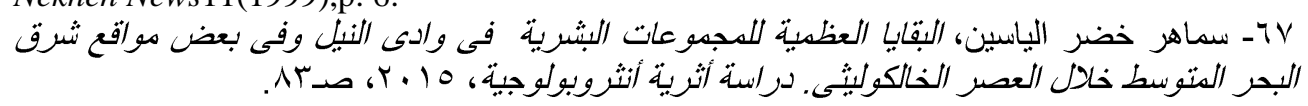
68- A. MAISH, opcit, p.6- 7.

69- X. DROUX, A. PIERI, " Further adventures at HK6: the 2010 season" Nekhen News22(2010), p. 4.

70- Ipid.

71- S. P. DOUGHERTY, "Death in fragments: piecing together the skeletons of HK6" Nekhen News22(2010), p. 7.

72- L. RAISTON, "Exploring the Secret of the Gebel", Nekhen News14(2002), p.19.

73- STEVENSON A., The Predynastic Egyptian Cemetery at El-Gerzeh. Social identities 
and mortuary practices, OLA 186, p. 100

74- TAMORRI V., in HORN M. eds., Current Research in Egyptology 2010. Proceedings of the eleventh annual symposium leiden University 2010, 2010, p. 178.

75- M. KOBUSIEWICZ, J. KABACIŃSKI, "Cemeteries", Gebel Ramlah. final Neolithic cemeteries from the western desert of Egypt, in: M. KOBUSIEWICZ eds., Institute of Archaeology and Ethnology Polish Academy of Sciences Poznań Branch, Poznań 2010, p. 251.

76- M. KOBUSIEWICZ etal., op.cit, p. 32.

77- W.E.POTTER, J. F. POWELL, "Big headaches in the Predynastic: Cranial trauma at HK43" Nekhen News15(2003), p. 26-27.

78- A. MAISH, "Not just another cut throat" Nekhen News15(2003), p. 26.

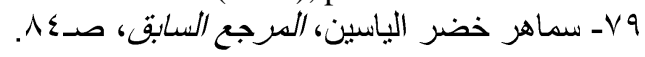

80- R. FRIEDMAN, "A basket of delights: the 2003 excavations at HK43" Nekhen News 15(2003), p. 19

81- VALTORTA E., in: GRZYBOWSKA J. P. eds., The Pultusk Academy of Humanities. Acta Archaeologica Pultuskiensia, V.II, 2009, p. 198.

82- S. P. DOUGHERTY, "Death in fragments: piecing together the skeletons of HK6" Nekhen News22(2010), p. 7.

83- W.E.POTTER, J. F. POWELL, "Big headaches in the Predynastic: Cranial trauma at HK43" Nekhen News15(2003), p. 27.

84- TAMORRI V., "The manipulation of human remains in Predynastic Egypt: preliminary observations", in HORN M. eds., Current Research in Egyptology 2010. Proceedings of the eleventh annual symposium leiden University 2010, 2010, p. 179.

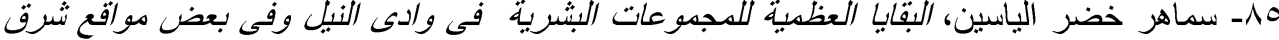

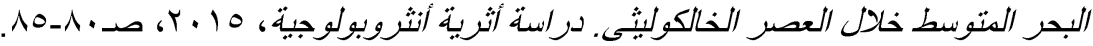

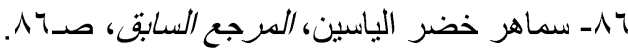

87- A. MAISH, «Trauma at HK43», Nekhen News10(1998), p. 7.

88- VALTORTA E., "The ritualised body: body treatment and ritual practices in Egyptian Predynastic burials", in: GRZYBOWSKA J. P eds., The Pultusk Academy of Humanities V.II, 2009, p.196.

89- Ibid, P. 199.

90- Ibid, p. 205.

$$
\text { 19 ـ تقع البدارى فى مصر الوسطى حوالى ، بكم الى الجنوب من أسيوط: }
$$

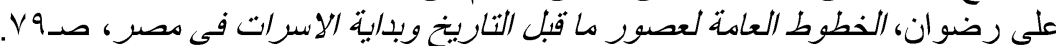
92-M. A. MURRAY, "Burial Customs and Beliefs in the Hereafter in Predynastic Egypt", JEA 41, p. 87

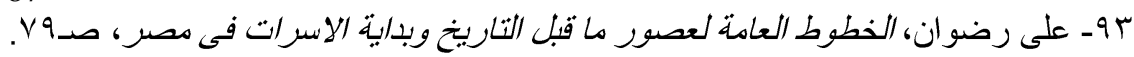
94- VALTORTA E., "The ritualised body", in: J. P. GRZYBOWSKA eds., The Pultusk Academy of Humanities, V.II, 2009, p.199, fig. 1.

95- WENGROW D., BAINES J., in HENDRICKX S. eds., Egypt at its origins. Studies in memory of ADAMS B., OLA 138, p. 1098

96- Ipid.

Vو - عمر فاروق محمد، النعام فى الحباة اليومبية والمعتقدات الدينية فى مصر القدبية من العصر الحجرى

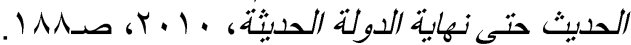

98- VALTORTA E., "The ritualised body: body treatment and ritual practices in Egyptian Predynastic burials", in: GRZYBOWSKA J. P eds., The Pultusk Academy of Humanities V.II, 2009, p.199.

99- WENGROW D., BAINES J., in HENDRICKX S. eds., Egypt at its origins. Studies in memory of ADAMS B., OLA 138, p. 1102.

100-M. A. MURRAY, "Burial Customs and Beliefs in the Hereafter in Predynastic Egypt", JEA 41, p. 92.

1 ـ اـ عبد العزيز صالح، حضارة مصر القدبية وآثار ها فحى الاتجاهات الحضاربة العامة حتى أواخرالالف 


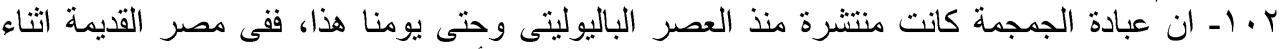

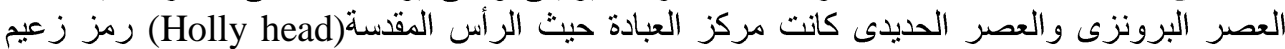

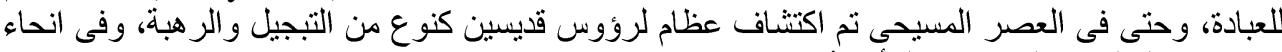

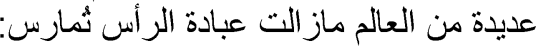

M. A. MURRAY, "Burial Customs and Beliefs in the Hereafter in Predynastic Egypt", JEA 41, p. 92.

ففى قصة الصراع بين اوزير وست عندما قطع ست جسد اخيه الى بـ قطعة ووزعهم فى اقاليم مصر الئر

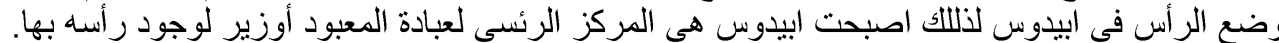

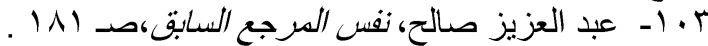

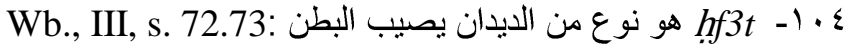

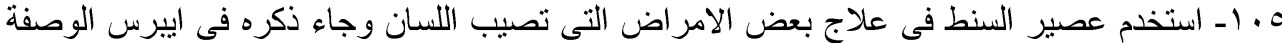

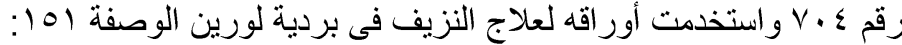

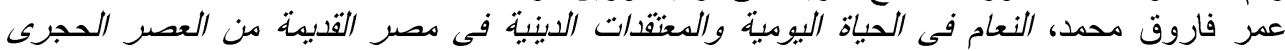

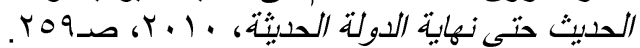

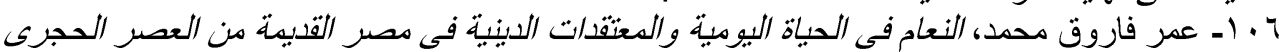

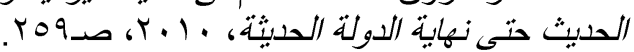

107- VALTORTA E., "The ritualised body: body treatment and ritual practices in Egyptian Predynastic burials", in: GRZYBOWSKA J. P. eds., The Pultusk Academy of Humanities. Acta Archaeologica Pultuskiensia, V.II, 2009, pp.195-196.

108- WENGROW D., BAINES J., opcit, p. 1101.

109- M. A. MURRAY, opcit, p.89.

110- WENGROW D., BAINES J., opcit, p. 1094.

الرسبائل العلمية:

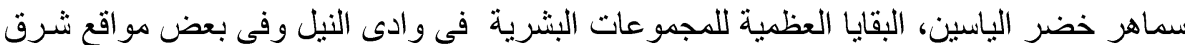

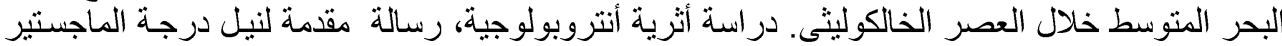

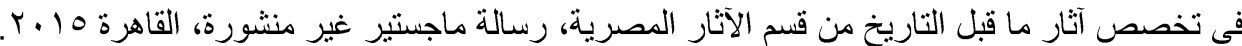

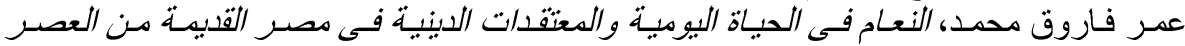

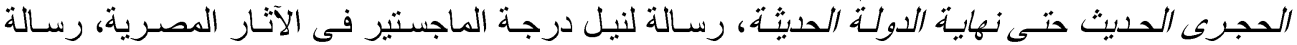

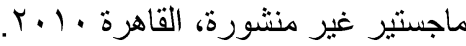

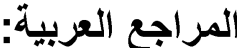

عبد العزيز صالح، حضارة مصر القدبية وآثار ها فيى الاتجاهات الحضارية العامة حتى أواخر الالف الثالث

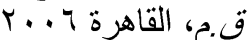

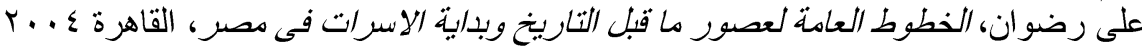

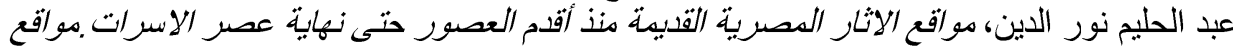

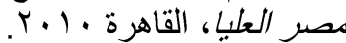

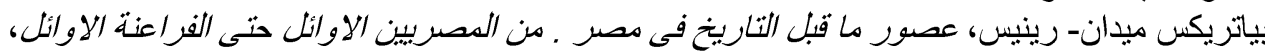

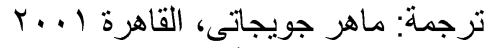

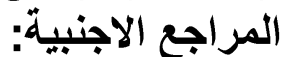

Wb I, III, IV, V

- SHMAKOV T. T., Critical analysis of J. p. ALLEN's "The ancient Egyptian pyramid texts", Omsk-Tricht, 2012.

A. MAISH, R. FRIEDMAN, «Pondering Paddy: Unwrapping the mysteries of HK43», Nekhen News11(1999), p. 6.

X. DROUX, A. PIERI, "Further adventures at HK6: the 2010 season" Nekhen News22(2010), p. 4-5-6. 
S. P. DOUGHERTY, "Death in fragments: piecing together the skeletons of HK6" Nekhen News22(2010), p.6-7.

L. RAISTON, "Exploring the Secret of the Gebel", Nekhen News14(2002), p.19- 20.

- STEVENSON A., The Predynastic Egyptian Cemetery at El-Gerzeh. Social identities and mortuary practices, OLA 186, 2009.

M. KOBUSIEWICZ, J. KABACIŃSKI, "Cemeteries", Gebel Ramlah. final Neolithic cemeteries from the western desert of Egypt, in: M. KOBUSIEWICZ eds., Institute of Archaeology and Ethnology Polish Academy of Sciences Poznań Branch, Poznań 2010, pp. 7-117, figs. 1- 111, tabs. 1-17.

- WENGROW D., BAINES J., "Images, human bodies and the ritual construction of memory in late predynastic Egypt", in S. HENDRICKX eds., Egypt at its origins. Studies in memory of ADAMS B., OLA 138, 2004, p. 1081- 1113.

M. A. MURRAY, "Burial Customs and Beliefs in the Hereafter in Predynastic Egypt", JEA 41, 1955, p. 94.

- TAMORRI V., "The manipulation of human remains in Predynastic Egypt: preliminary observations", in HORN M. eds., Current Research in Egyptology 2010. Proceedings of the eleventh annual symposium leiden University 2010, 2010, pp. 175- 182.

R. FRIEDMAN, WATRALL E., JONES J., FAHMY A. G., NEER, V. LINSEELE W. V., "Excavations at Hierakonpolis", Archéo Nil 12, 2002, pp. 55- 68, figs. 1-15.

R. FRIEDMAN, «More mummies: The 1998 season at HK43» Nekhen News10(1998).

- HASSAN F. A., "Between man and goddess: the fear of nothingness \& dismemberment", in HENDRICKX S. eds., Egypt at its origins. Studies in memory of ADAMS B. ,OLA 138, 2004, p. $779-801$.

A. MAISH, "Not just another cut throat" Nekhen News15(2003).

R. FRIEDMAN, "A basket of delights: the 2003 excavations at HK43" Nekhen News15(2003), pp. 18- 19

A. MAISH, «Trauma at HK43» Nekhen News10(1998).

W.E.POTTER, J. F. POWELL, "Big headaches in the Predynastic: Cranial trauma at HK43" Nekhen News15(2003), p. 26-27.

- VALTORTA E., "The ritualised body: body treatment and ritual practices in Egyptian Predynastic burials", in: GRZYBOWSKA J. P. eds., The Pultusk Academy of Humanities. Acta Archaeologica Pultuskiensia, V.II, 2009, pp.195-205.

http://www.alriyadh.com/814467

المواقع الاكترونية

https://www.altibbi.com

http://arabteb.com/disease

http://dictionary.reference.com

https://ar.wikipedia.org/wiki 